\title{
Exploring the capacity of renewable energy consumption to reduce outdoor air pollution death rate in Latin America \& the Caribbean region
}

\author{
Matheus Koengkan ${ }^{1}$, José Alberto Fuinhas ${ }^{*}, 2$, Nuno Silva ${ }^{3}$ \\ ${ }^{1}$ Rectory, University of Trás-os-Montes and Alto Douro, Vila Real, Portugal \\ ${ }^{2}$ CeBER, and Faculty of Economics, University of Coimbra, Coimbra, Portugal \\ ${ }^{3}$ CeBER, and Faculty of Economics, University of Coimbra, Coimbra, Portugal
}

\begin{abstract}
The impact of renewable energy consumption on reducing the outdoor air pollution death rate, in nineteen Latin America \& the Caribbean countries, from 1990 to 2016, using the econometric technique of Quantile Regression for Panel Data, was researched. Results show that economic growth, and fossil fuel consumption, are positively related to $\mathrm{CO} 2$ emissions, while renewable energy consumption bears a negative relationship with it. Furthermore, fossil fuel consumption has a positive impact on the mortality rate and economic growth a negative one. The negative effect of renewable energy consumption on the mortality rate is only observable on the right tail of its distribution. The modelisation reveals two ways in which the consumption of renewable energy can reduce the outdoor air pollution death rates: (i) directly, by increasing renewable energies; and (i) indirectly because the increase in the consumption of renewable energies implies a decrease in the consumption of energy from fossil fuels. The phenomenon of increasing urbanisation is a point where the action of public policymakers is decisive for the reduction of outdoor air pollution death rates. Here, the question is not to reduce the level of urbanisation but to act on the "quality" of urbanisation, to make cities healthier. The research concludes that public policymakers must focus on intensifying the transition from fossil to renewable energies and improving the quality of cities.
\end{abstract}

Keywords: Econometrics; Environmental economics; Health economics; Macroeconomics; Pollution; Renewable energy.

Acknowledgements: CeBER R\&D unit funded by national funds through FCT - Fundação para a Ciência e a Tecnologia, I.P., project UIDB/05037/2020.

\footnotetext{
* Corresponding author: : fuinhas@uc.pt; Faculty of Economics, University of Coimbra, Av. Dias da Silva 165, 3004-512 Coimbra, Portugal.

${ }^{1}$ Rectory, University of Trás-os-Montes and Alto Douro, Vila Real, Quinta de Prados, 5000-801, Vila Real, Portugal.

${ }^{2}$ CeBER, and Faculty of Economics, University of Coimbra, Av. Dias da Silva 165, 3004-512 Coimbra, Portugal. Research supported by: CeBER, R\&D unit funded by national funds through FCT - Fundação para a Ciência e a Tecnologia, I.P., project UIDB/05037/2020.

${ }^{3}$ CeBER, and Faculty of Economics, University of Coimbra, Av. Dias da Silva 165, 3004-512 Coimbra, Portugal. Research supported by: CeBER, R\&D unit funded by national funds through FCT - Fundação para a Ciência e a Tecnologia, I.P., project UIDB/05037/2020.
} 


\section{Introduction}

Air pollution is a problem that is responsible for more than 5 million deaths each year in the World (IHME, 2018). Moreover, the air pollution problem according to Romieu et al. (1990) is a combination of outdoor and indoor gases (e.g., household air pollution particulates, ammonia, carbon monoxide, sulfur dioxide, nitrous oxides, methane, chlorofluorocarbons, ambient fine particulate matter, and lead). Indeed, according to Ritchie and Roser (2020) and IHME (2018) these gases, when emitted into the atmosphere are responsible for many of the leading causes of death (e.g., lung cancer and chronic obstructive pulmonary disease, diabetes, respiratory infections, stroke, and heart disease).

The impact of air pollution on premature mortality and disease revealed to be more pronounced in lowand middle-income countries than in high-income ones (e.g., Balakrishnan et al., 2019; Landrigan et al., 2018; Cohen et al., 2017). The process of urbanisation and growing industrialisation in addition to the industrial processes in the large cities, and consumption of fossil fuels by households, firms, industries are responsible for the increase in the air pollution problem and consequently these deaths (Li et al., 2020; Bayat et al., 2019; Romieu et al., 1990). This idea is followed by EPA (2018), and Pablo-Romero et al. (2016), where along with the authors, in the last century, the economic growth of developed and developing countries was accompanied by a surge in energy consumption, mostly from fossil fuels. This process led to an increase in the emissions of hazardous pollutants, which caused environmental degradation and had adverse impacts on human health and mortality. Indeed, in the World, the electricity and heat production sector accounted $25 \%$ of the total of air pollution in 2010 , Agriculture, Forestry and Other Land Use (AFOLU) sector, 24\%, industry sector, 21\%, transport sector, 14\%, other energies, $10 \%$, and buildings sector, $6 \%$ (see Figure 1).

- Electricity and heat
production
- AFOLU
- Industry
$\square$ Transport
$\square$ Other energy
Buildings

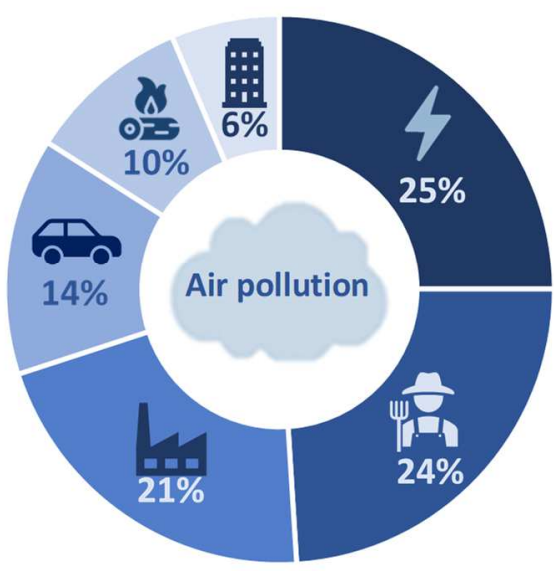

Figure 1. Air pollution in the World per sector in 2010. This figure was created by the author and based on the FGV Energia (2016).

Moreover, more than $80 \%$ of people living in these urban areas are exposed to air quality levels that exceed the World Health Organization (WHO) guideline limits, where the low-and middle-income countries were suffering from the highest exposures of outdoor air pollution (WHO, 2020). Latin America and the Caribbean (LAC) region is not an exception, where the countries from this region have registered a growth in the air pollution exposure between 1990-2014 (see Figure 2). 


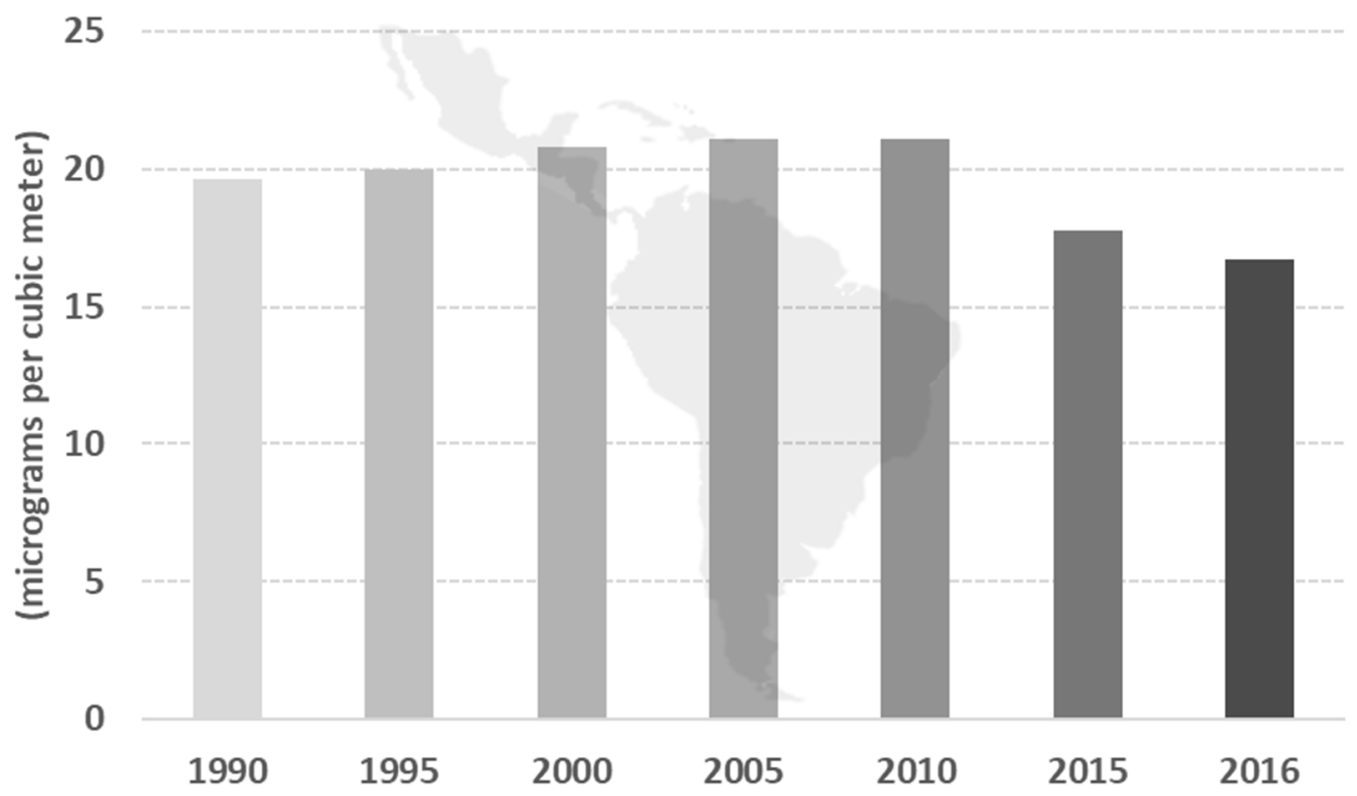

Figure 2. PM2.5 air pollution, mean annual exposure (micrograms per cubic meter) in the LAC region between 1990-2016; This figure was created by the author and was based on the database from the World Bank Open Data (2020).

Indeed this growth was caused by high urbanisation trends where $79 \%$ of the population of the region live in urban areas, and by economic liberalisation (e.g., trade and financial) that intensified during the period between 1989-1992, and 2004-2014 and that consequently encouraged the rapid increase in the demand of energy and the air pollution (Koengkan and Fuinhas, 2020a Koengkan and Fuinhas, 2020b; Riojas-Rodríguez et al., 2016). Indeed, in the LAC region, the electricity and heat production sector accounted $48 \%$ of the total air pollution in 2014 , AFOLU sector, 23\%, industry sector, $4 \%$, and waster $6 \%$ of air pollution emissions (see Figure 3).

- Electricity and heat
production
- AFOLU
- Industry
- Waste

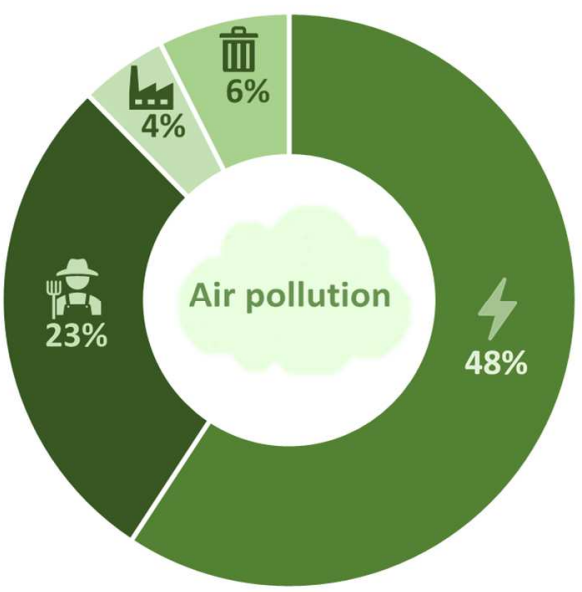

Figure 3. Air pollution in the LAC region per sector in 2014. This figure was created by the author based on the FGV Energia (2016).

However, as can be seen in Figure 4, the outdoor air pollution in the region has been decreasing since 2015 due to the biggest insertion of new energy sources. Moreover, the death rates from outdoor air pollution that measure the number of deaths per 100,000 population were 27.8 in 1990, and this value dropped to 24.04 in 2016 . 


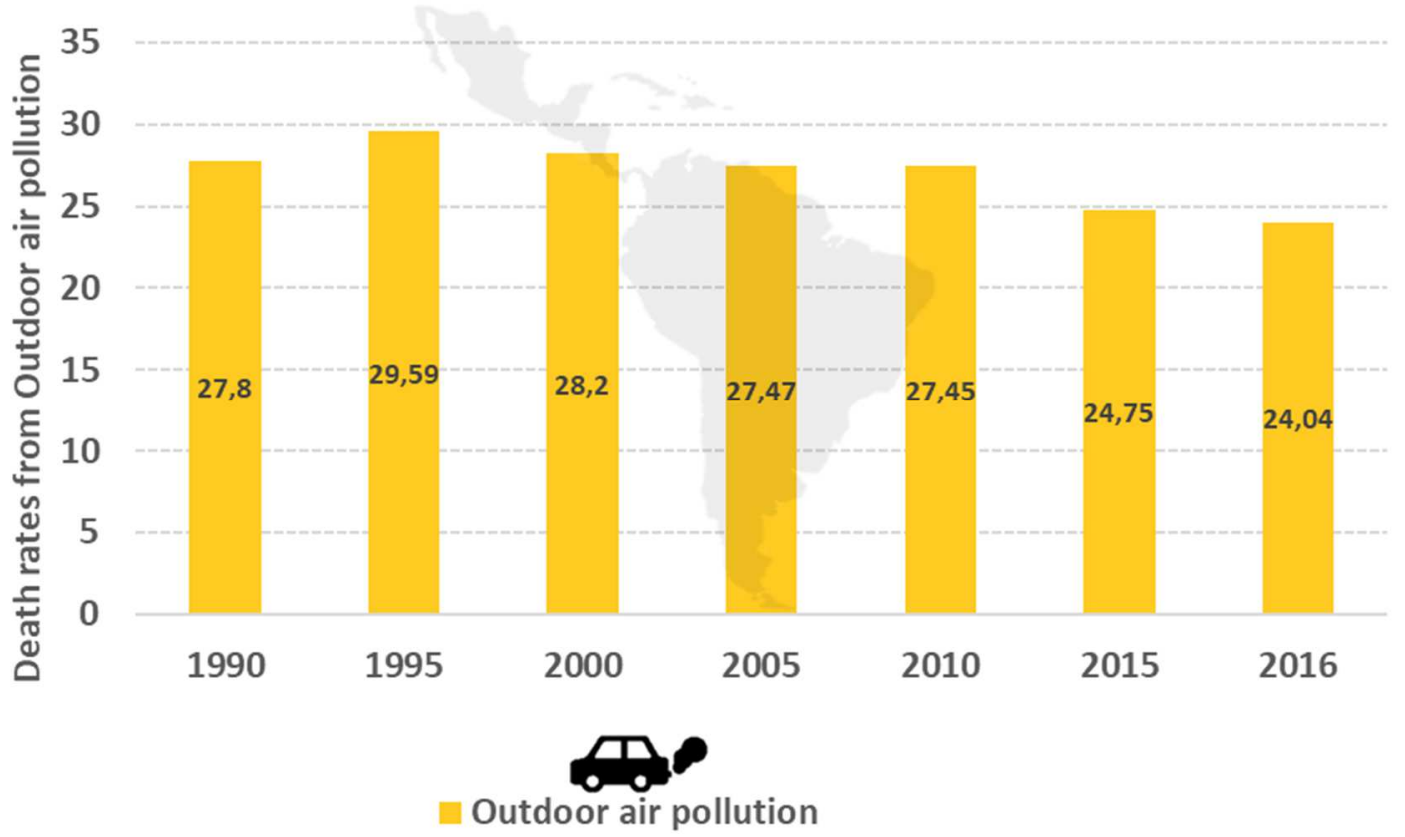

Figure 4. Evolution of Outdoor air pollution death rates (deaths per 100,000) in Latin America \& Caribbean (1990-2016). This graph was created with the database from the Our World in Data (2020).

Indeed, the slow growth in the air pollution exposure and the significant decrease in the deaths from outdoor air pollution between 1990 to 2016 coincides with the rapid intensification in the process of the energy transition in the region (Koengkan et al. 2019a). This rapid process of the energy transition was caused by the rapid development of new renewable energy sources (e.g., biomass, geothermal, solar, photovoltaic, waste, and wind) during the 1990 s to 2016 , where this kind of sources comprised only $5,03 \%$ of total installed capacity of energy in the region in 2016, where the wind energy comprised $2,12 \%$, solar energy $0,40 \%$, and other renewable energy that includes geothermal, biomass, and waste comprised 2,51\%. Moreover, the large hydropower dam plants also had rapid growth in this period, where the participation of this kind of energy in the energy matrix reached a value of 23,57\% (see Figure 5). However, the investments in large hydropower dam plants have been declining in the LAC region in the last decades due to the investments in new renewable energy sources. 


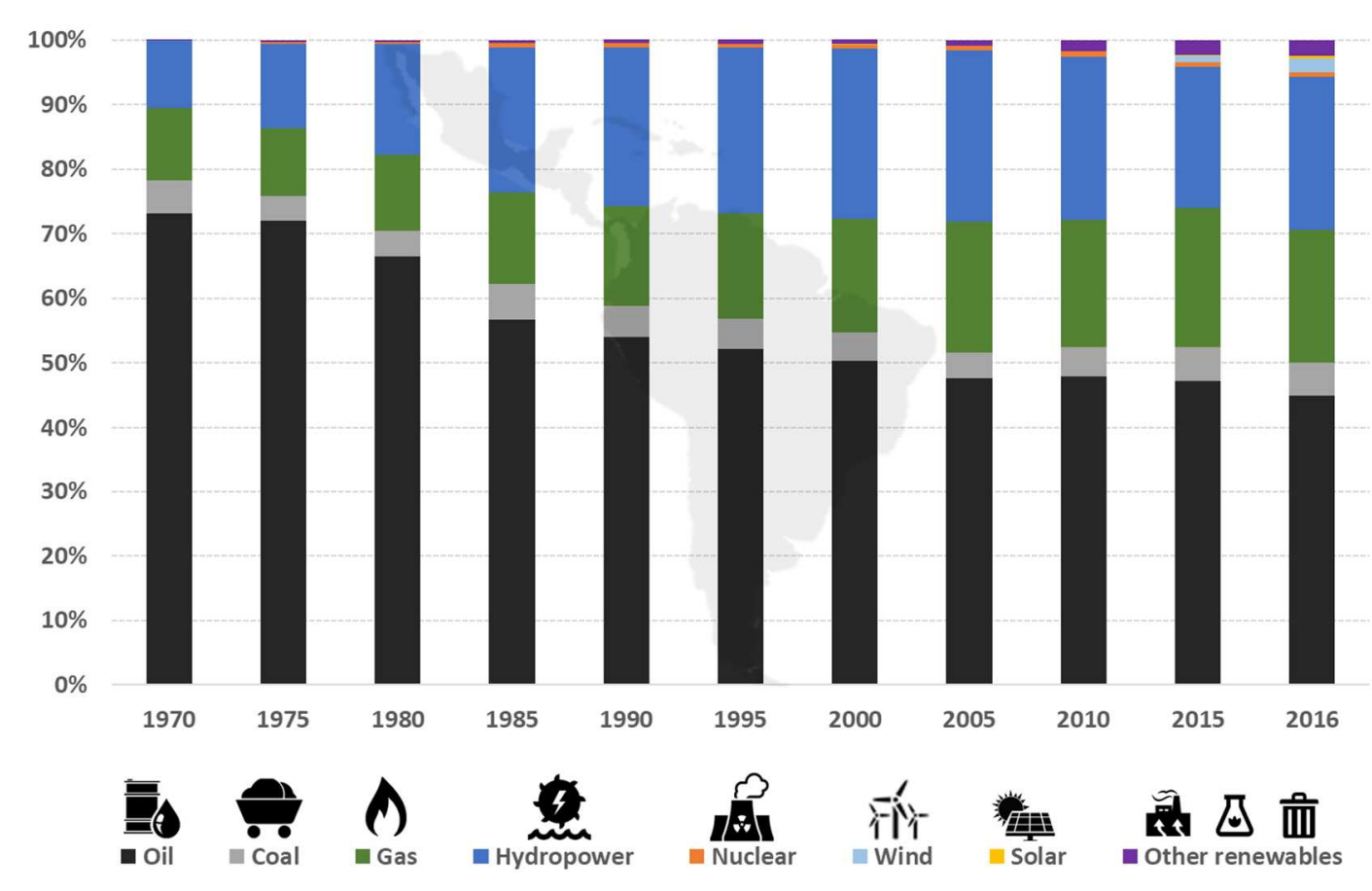

Figure 5. Share of energy sources in the LAC region energy matrix between 1970-2016; Other renewables include geothermal, biomass and waste energy; This figure was created by the author and was based on the database from the Our World in Data (2020).

However, in the main countries of the LAC region such as Mexico, the renewable energy sources accounted for 5,91\% of total energy matrix in 2016, in Argentina accounted for 10,74\%, in Chile accounted for $18,56 \%$, while in Brazil accounted for incredible $36,40 \%$ of the total energy matrix (see Figure 6). 

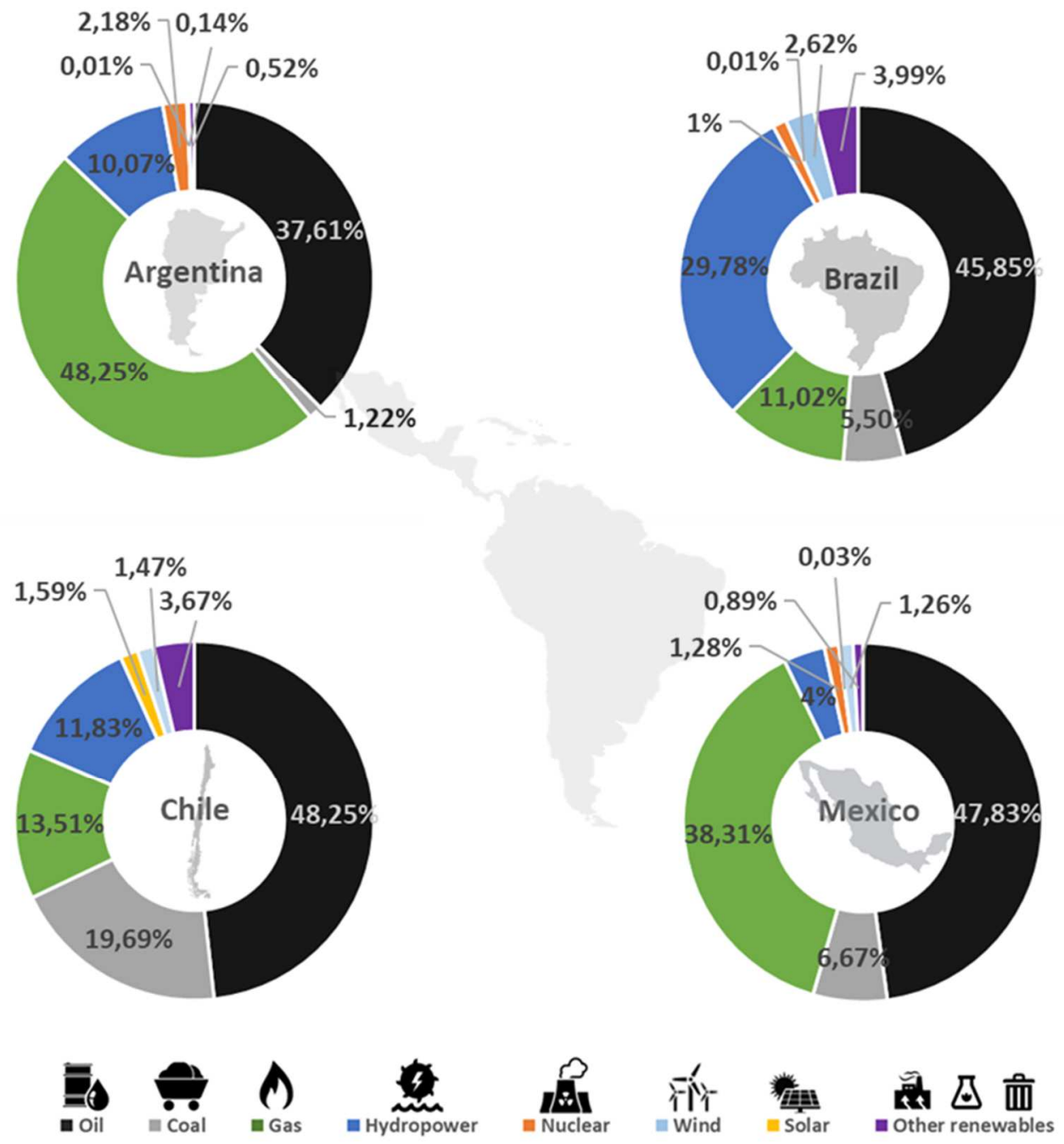

Figure 6. Share of energy sources in Argentina, Brazil, Chile, and Mexico, in 2016; Other renewables include geothermal, biomass and waste energy; This figure was created by the author and was based on the database from the Our World in Data (2020).

Moreover, between 1990 and 2016, the installed capacity of these energy sources was 360 Terawatt-hours (TWh) in 1990 and reached a value of 814 TWh in 2016. This increase is related to large investments in biomass and waste and by wind, geothermal, and also solar and large hydropower dam plants which make up most of this growth (see Figure 7). 


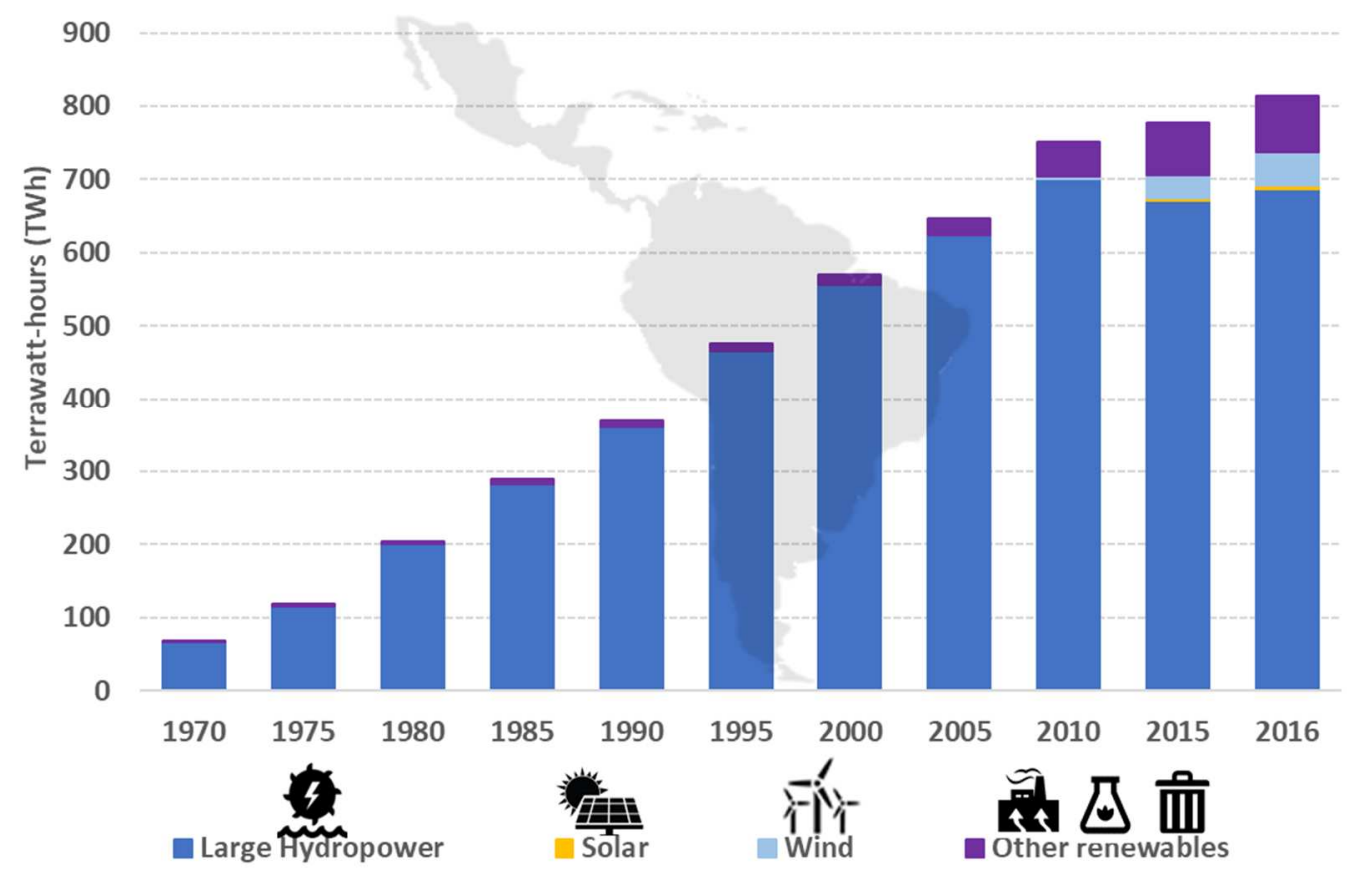

Figure 7. Installed capacity of renewable energy in the LAC region energy matrix between 1970-2016; Other renewables include geothermal, biomass and waste energy; The installed capacity is measured in terawatt-hours (TWh); This figure was created by the author and was based on the database from the Our World in Data (2020).

This increase in the installed capacity of renewable energy in the region is a result of high investment in renewable energy technologies that was 1.6 US\$ billion in 2004, and in 2016 reached 8.7 US\$ billion (see Figure 8). That is, the period between 2000 and 2013, the investment renewable energy technologies grew $13 \%$ between (Koengkan and Fuinhas, 2020a).

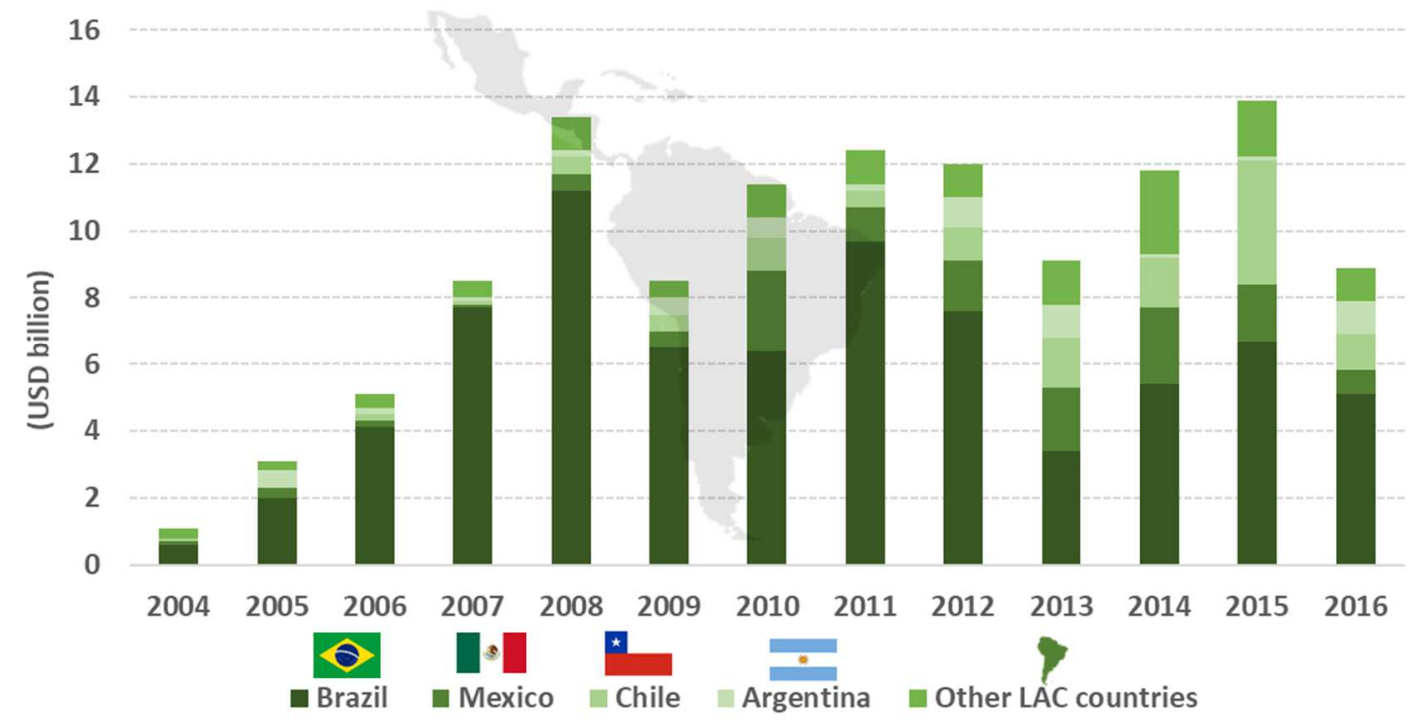

Figure 8. Investment in new renewable energy sources in USD billion in the LAC region, between 20042016; This figure was created by the author and was based on the data from the BloombergNEF (2020).

This rapid expansion of renewable energy in the LAC region is also associated with the fast process of economic liberalisation as mentioned before that began in the 1990s, after the implementation of neoliberal policies during the process of the "Washington consensus", which is a combination of measures to promote the 
"macroeconomic adjustment", as well as by the "Brady Plan" which was an external debt restructuring plan (Koengkan and Fuinhas, 2020a). This process of macroeconomic adjustment occurred between 1989 and 1992 , where several countries from the region adopted this strategy such as Costa Rica and Mexico in 1989, Venezuela (RB) in 1990, Uruguay in 1991, Argentina and Brazil in 1992 (Koengkan and Fuinhas, 2020b). All these countries according to Aizenman (2005) and Vásquez (1996) passed by a deep process of trade and financial liberalisation, in addition to the process of privatisation of significant portions of the public sector.

However, this process of liberalisation in the region intensified with the "commodities boom" that occurred between 2004 to 2014, where the region had an average growth rate of $7.40 \%$ (Koengkan and Fuinhas, 2020a). That is the commodities boom that occurred in the LAC region impacted the degree of economic openness, where the countries of this region created a dependence on external demand (Carneiro, 2012). This process of liberalisation during 1989-1992, and between 2004-2014, as mentioned before exerted a positive impact on economic growth, where the LAC's GDP per capita growth (annual \%) had an average annual growth rate of approximately 2,67\% between 1989 to 2016 (see Figure 9).

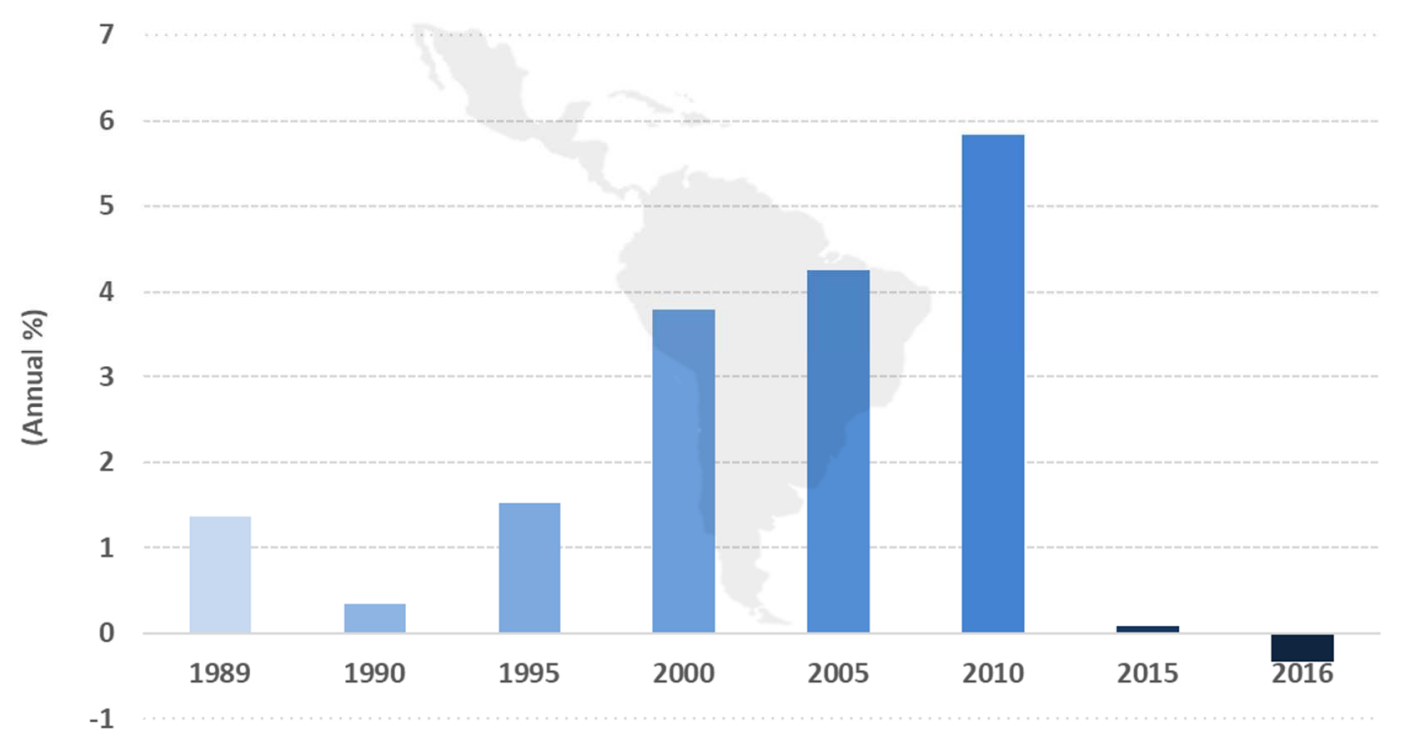

Figure 9. GDP growth (annual \%) in the LAC region between 1989-2016; This figure was created by the author and was based on the database from World Bank Open Data (2020).

As well as, the energy consumption, wherein 1990, the electric power consumption in Kilowatt-hour (kWh) per capita in the region was $1175,97 \mathrm{kWh}$, and in 2014 the consumption had reached a value $2155,70 \mathrm{kWh}$ (see Figure 10). 


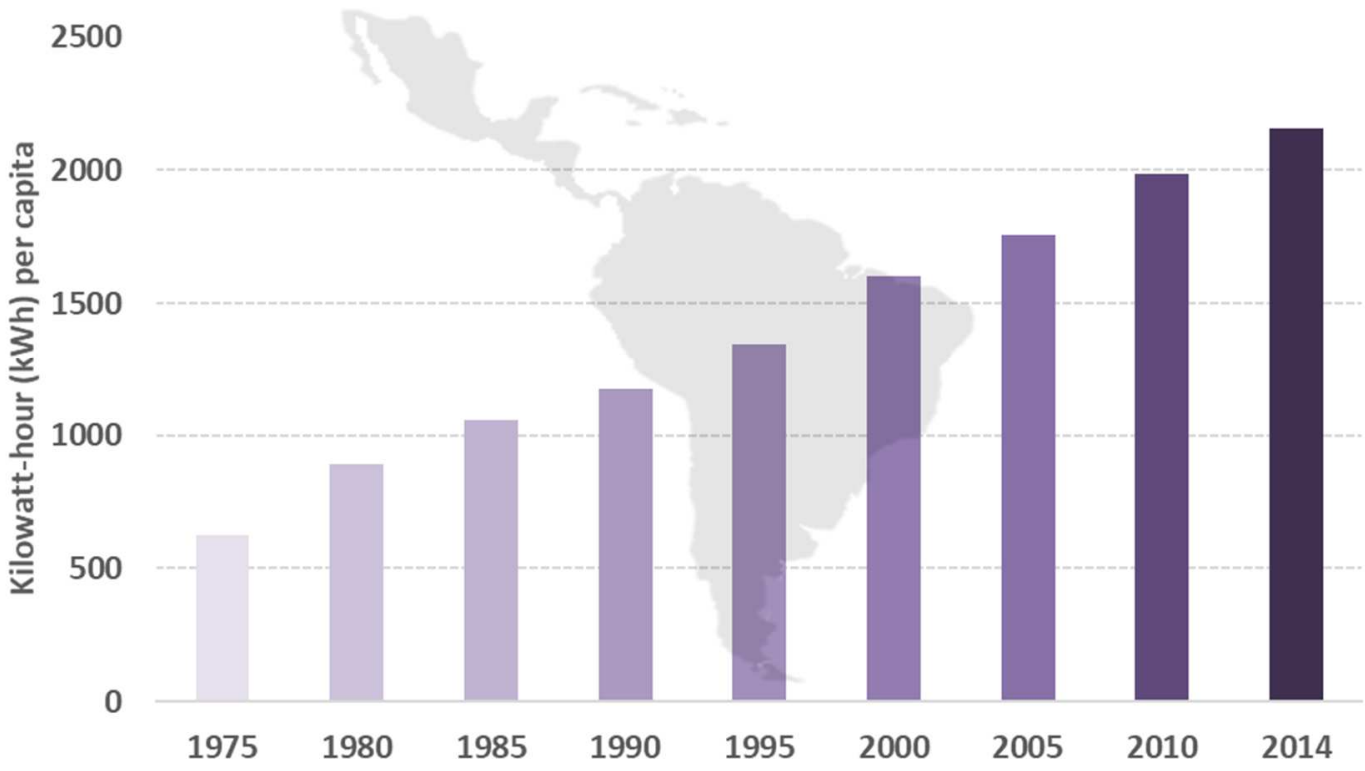

Figure 10. Electric power consumption (kWh per capita) in the LAC region; This figure was created by the authors and was based on the database from World Bank Open Data (2020).

However, to meet the energy demand, new investments in renewable energy technologies were necessary (Koengkan et al., 2019b). Additionally, this same process of liberalisation also facilitated the introduction of new renewable energy technologies via trade liberalisation that consequently contribute to the increase in the installed capacity and consumption of this kind of energy in the region (Koengkan et al., 2019c). Moreover, the LAC region faces the difficult challenge of fostering economic development and reducing poverty, without increasing their reliance on fossil fuels. It is in an enviable position to accomplish this goal because it has been blessed by exceptional natural conditions to produce energy from renewable sources (Aghahosseini et al., 2019; Shahsavari and Akbari, 2018; Barbosa et al., 2017; Griffith-Jones et al., 2017). It can also benefit from the steady decline of the wind and solar levelised costs of energy. Unfortunately, recent figures show that the promotion of renewable energy sources in Latin American countries has been insufficient to avoid a decrease in their share of total energy consumption (Washburn and Pablo-Romero, 2019).

Based on the events described above, we created the following main research question of this investigation. Can renewable energy consumption decrease the deaths from outdoor air pollution in Latin America and the Caribbean region? The main research objective is to identify the effects of renewable energy consumption on deaths from outdoor air pollution in a group of nineteen countries from the LAC region for the period from 1990 to 2016. The empirical approach was performed recurring to the new Quantile via Moments model approach that was introduced by Machado and Silva (2019). Indeed, the quantile regression is more flexible than traditional least square methods (e.g., Onyedikachi, 2015), as it allows the marginal effects of the covariates to change across the population, whereas the latter only captures the impact of the covariates on the conditional mean. This feature proved to be crucial in our study because the effects of the explanatory variables on outdoor pollution death rate and $\mathrm{CO} 2$ emissions do change across the distribution. Furthermore, unlike least square methods, whose estimates are very sensitive to the presence of outliers, in quantile regressions, the influence of outliers on conditional quantiles is bounded and depends only on the sign of the residuals (Koenker, 2005). Lastly, least-square methods usually rely on the assumption that variables are normally distributed, while quantile methods are distribution agnostic.

The motivation that drives the realisation of this investigation is related by the necessity of deepening or expand the knowledge regarding the effect of renewable energy consumption in other scientific areas such as health and show that the increase of renewable energy consumption caused by the process of the energy transition can cause positive health effects. That is, the increase in consumption of renewable energy caused by energy transition can reduce the air pollution mortality from low- and middle-income countries, such as the LAC countries that suffering from diseases caused by air pollution, and consequently can improve the life expectancy in these countries.

Moreover, the investigation's contribution to literature is twofold. Firstly, we evaluate the impact that renewable energy has exerted on the deaths from outdoor air pollution in the LAC region. We conceive an 
econometric model linking the deaths from outdoor air pollution with economic growth, carbon dioxide emissions, consumption of renewable energy, consumption of fossil fuels and urbanisation. These explanatory variables, by themselves, do not directly cause the mortality that we are trying to explain, but they are correlated with the generation of toxic pollutants, which may be responsible for an increase in respiratory and cardiovascular diseases and, ultimately, death. Thus, our work provides an indirect assessment of the impact hazardous pollutants, that are correlated with our explanatory variables, have on the mortality rate in the LAC region. Simultaneously, the individual contribution of each variable could be assessed and let as to percept if the energy transition from fossil to renewables materialises in the quality of public health. Secondly, we use a panel quantile estimator with individual effects to check whether the impact of renewable energy and the control variables on the deaths from outdoor air pollution in LAC countries is homogeneous throughout their distributions.

The remainder of this study is organised as follows. In the next section, we conduct a literature review on the relationship between economic growth and pollution, and the association between pollutant concentrations and mortality rates. In section 3, we describe the methodology and the dataset. In section 4, we present the main results, and, in section 5, we discuss them. Finally, section 6 concludes the paper.

\section{Literature review}

In this Section will be presented a brief review of the debate linking economic growth, urbanisation, and consumption of fossil fuels with air pollution and mortality. Air pollution encompasses a mix of voluminous pollutants. Among the significant components present in the air pollution there are: (i) the household air pollution; (ii) the ambient particulate matter pollution; and (iii) the ambient ozone (troposphere). The main sources of household air pollution are the residential burning of solid fuels (mainly wood, charcoal, dung, residues, and coal) for cooking and heating. The ambient particulate matter pollution results primarily from coal-burning (thermal power generation), emissions (industrial, construction, brick ovens and motorised vehicles), the road dust, burning (biomass, waste, agricultural residues), and diesel generators. Ambient ozone was produced at ground-level because of the reaction of nitrogen oxides and volatile organic compounds, in the presence of sunlight. The main emitters are the motorised vehicles, power generation plants, and industries. As developing countries grow, they inevitably are exposed to challenging constraints from air pollution.

The level of air pollutant depends on temperature, wind speed, and rainfall. Indeed, most of the air pollutants, exhibit pronounced seasonal patterns because of weather (Bharadwaj et al., 2017). Indeed, the level of concentration of air pollutants on one location is conditional on the different sources of emissions, as well as, the weather and seasonal patterns.

\subsection{Economic growth and air pollution}

The relationship between economic growth and air pollution has drawn the attention of researchers worldwide. According to the Environmental Kuznets Curve (EKC), popularised by Grossman and Krueger (1991), there is an inverted U-shaped relation between per capita air pollution and per capita GDP. In the early stages of economic development, growth generates a higher level of pollution, but, at later stages, society becomes increasingly concerned about environmental preservation and pollution declines. Alvarez-Herranz et al. (2017) argue that there is a third stage disregarded by the supporters of the traditional EKC, where technical obsolescence in high-income countries drives the $\mathrm{CO}_{2}$ emissions up once again. Despite the voluminous literature that focuses on the relation between air pollution and economic growth, this issue remains unsettled and deserves further research. Amongst the studies that focus mainly in LAC countries, some are consistent with the EKC hypothesis (Hanif, 2017; Sapkota and Bastola, 2017), while others report a monotonically positive association between economic growth and $\mathrm{CO}_{2}$ emissions (Pablo-Romero and Jesus, 2016; Jardón et al., 2016; Van-Ruijven et al., 2016). This inconclusive pattern is also observed in research involving an extended set of countries from different continents, where the shape of the relation between air pollution and economic growth depends on the specific pollutants considered, the countries and period, as well as the methodology selected (Hove and Tursoy, 2019; Yao et al., 2019; Rasli et al., 2018; Bilgili et al., 2016).

Renewable energy sources are believed to mitigate the impact of economic growth on $\mathrm{CO}_{2}$ emissions and can lead to anticipation in the turning point of the EKC (Alvarez-Herranz et al., 2017). Most research on this subject involving Latin American countries is consistent with this hypothesis (Koengkan et al., 2019a; Yao et al., 2019; Koengkan et al., 2019b; Koengkan, 2018; Ito, 2017; Fuinhas et al., 2017; Özbuğday and Erbas, 2015; Robalino-López et al., 2015; Shafiei and Salim, 2014), but some authors reach the opposite conclusion (Zaman and Moemen, 2017; Apergis et al. 2010).

\subsection{Urbanisation}

The exposure to air pollution is particularly acute at the city level, where the level (of fine) particle concentration from local traffic represents a challenging threat to public health. These problems grew up with rapid urbanisation, intensification of traffic due to growing demand for road transportation, and in many cases because 
of a combination of low-quality fuels, old and poorly maintained vehicles. Indeed, the problem is acute in the presence of high rates of urbanisation.

Air pollution is increasingly recognised as a serious threat to population health as it damages buildings, disturbs the ecosystem, and limits visibility. Air pollution has been more and more linked with the increasing levels of the most prevalent chronic diseases and the hospital and emergency department visits, as well as with decreases in life expectancy and an increasing loss of work and school days (Brønnum-Hansen et al., 2018; Nasari et al., 2016).

The urban traffic-related air pollution exposes the city dwellers to NO2 emissions and ultrafine particles that are mainly originated from diesel-powered vehicles. Reducing the NO2 emissions exposure to control trafficrelated air pollution requires considerable investments in public transportation, creative traffic management, improving fuel quality, promoting modes of transportation, and expanding low emission zones. The stance of economic growth is a significant driver in the capacity to burden the costs of transition to urban health areas. The extension of problems that air pollution put to economic viability manifests itself in several ways. For example, air pollution has also affected tourism adversely and induced the moving out of highly polluted cities as documented for China (Becken et al., 2016).

\subsection{Consumption of fossil fuels}

The developing countries have faced quite a few specific containments that have limited their ability to circumvent the damage for public health that come from the consumption of fossil fuels. Even the evidence from developed economies cannot promptly be reassigned to the developing countries. The dissimilar cultures, contexts and institutions represent an obstacle that empties its usefulness.

The main barriers to adopt policies (economic, social, environmental, and health) in developing countries come from them facing constraints on their regulatory capacity to enforce environmental regulations. For example, improving fuel standards by imposing fuel quality is very important in urban areas. The welfare consequences of low enforcement of environmental regulations reveal to be particularly severe in densely populated areas or fastgrowing cities. Another source of concern is the industry opposition. Governments have been confronted with limited financial resources and scarce qualified staff (e.g., International Council on Clean Transportation, 2010) to be able to change the situation.

The consumption of fossil fuels is a significant contributor to air pollution because the exhaust emission from internal vehicles' combustion engines (especially heavy-duty diesel-powered vehicles) contains large amounts of toxics, mainly nitrogen oxides and ultrafine particles. Traffic-related air pollution generates exposure to NO2 that increase the incidence and prevalence of major respiratory, chronic cardiovascular, metabolic diseases, lung cancer, and a decrease in disease-free life expectancy (e.g., Brønnum-Hansen et al., 2018).

\subsection{Air pollution and mortality}

Several epidemiological studies have linked air pollutants to adverse health outcomes. Ambient fine particulate matter pollution poses a considerable risk to people because the exposure to particles can result in them penetrating deep into the lungs and remain there for long periods. Ambient and household exposure to ambient fine particulate matter pollution increase the relative risks for mortality from acute lower respiratory infections, chronic obstructive pulmonary disease, ischaemic heart diseases, stroke, lung cancer, and diabetes.

Over the last decades, developing countries were confronted with health problems caused by the rapid industrialisation that has generated an unprecedentedly high level of air pollution. The air pollutants diffuse readily into indoor environments and are transported over long distances (Pope and Dockery, 2006). More explicitly, air pollution has been associated with an increased incidence of lung cancer, respiratory and heart disease mortality, and the aggravating of asthma (Pope and Dockery, 2013; Parry et al., 2007; Greenstone, 2004). Another important source of air pollution is the steady increase in ozone that provokes damages in human health and harvests.

The research on the impact of air pollution on mortality can be classified in two broad categories: (i) times series studies, which analyse the effect that short-term fluctuations in pollutants' concentration has on mortality rates; and (ii) cohort studies that require researchers follow a subpopulation over an extended period to assess the impact of long-term exposure to air pollution on mortality rates. In Latin America, most studies analyse the shortterm effect of increases in $\mathrm{PM}_{10}$ exposure on mortality, due to data availability, and report mild increases in mortality for São Paulo (Costa et al., 2017a; Costa et al., 2017b; Bravo et al., 2016; Gouveia and Fletcher, 2000), and for several other Latin American cities (Liu et al., 2019; Gouveia and Junger, 2018; Romieu et al., 2012; O'Neill et al. 2008). The analysis of the impact of $\mathrm{PM}_{10}$ concentration on mortality may provide misleading conclusions because it depends on the concentration of associated pollutants. Recognising this limitation, several authors studied other pollutants and found that sulphur dioxide (Gouveia and Junger, 2018; Bravo et al., 2016), nitrogen dioxide (Costa et al., 2017a, 2017b; Bravo et al., 2016), carbon monoxide (Costa et al., 2017a, 2017b; Bravo et al., 2016), and ozone (Costa et al., 2017a; Bravo et al., 2016; Gouveia and Fletcher, 2000) lead to increases in the mortality rate.

To the best of our knowledge, no cohort study investigates the long-term impact of pollution on Latin American countries. These studies require a vast amount of resources and take a long time to complete, which 
prevents most countries from conducting them. However, they may be more relevant to our research than timeseries ones because we analyse the evolution of mortality at a yearly frequency. Recently, three articles reviewed the cohort studies focusing on the association between $\mathrm{PM}_{2.5}$ exposure mortality rates and provided metaregression estimates of the impact size (Nabizadeh et al., 2019; Pope et al., 2019; Vodonos et al., 2018). These authors concluded that long-term exposure to $\mathrm{PM}_{2.5}$ adversely affects mortality rates, and its impact is at least as high as the short-term one.

\section{Method and data}

This Section is divided into two subsections. The first one (3.1.) presents the adopted method approach that will be used, and the Second (3.2.) describes the data and variables that will be used in this study.

\subsection{Method}

This subsection will show the method approach that this study will use. Therefore, to help to answer the central question, as well as answer the specific questions of this study, the Quantile via Moments model approach, was used. This method, introduced by Machado and Silva (2019), allows the estimation of conditional quantiles using panel data in the presence of individual effects, which, unlike in Canay (2011), maybe both location and scale shifters. Furthermore, it generates estimates of the regression quantiles that do not cross, which is fundamental in empirical studies. This method can provide information on how the regressors affect the entire conditional distribution. Moreover, according to Machado and Silva (2019), the Quantile via Moments model, given data $\left\{\left(Y_{i t}, X_{i t}^{\prime}\right)^{\prime}\right\}$ from a panel of $\mathrm{n}$ individuals $i=1, \ldots, \mathrm{n}$ over $T$ periods, is constructed around the following Equation (1):

$$
Y_{i t}=a_{i}+X_{i t}^{\prime} \beta+\left(\delta_{i}+Z_{i t}^{\prime} \gamma\right) U_{i t}
$$

with, $P\left\{\delta_{i}+Z_{i t}^{\prime} \gamma>0\right\}=1$. The parameters $\left(\alpha_{1}, \delta_{i}\right), i=1, \ldots, n$, capture the individual $i$ fixed effects and $\mathrm{Z}$ is a $\mathrm{k}$-vector of known differentiable (with probability 1 ) transformations of the components of $\mathrm{X}$ with element $l$ given by $Z_{l}=Z_{l}(X), \quad l=1, \ldots, k$. In empirical research, we will use a special case of Eq. (1), a linear heteroskedasticity model, in which $\sigma(\cdot)$ is the identity function, and $\mathrm{Z}=\mathrm{X}$. The sequence $\left\{X_{i t}\right\}$ is i.i.d. for any fixed $i$ and independent across $t$. $U_{i t}$ are i.i.d. (across $i$ and $t$ ), statistically independent of $X_{i t}$, and normalised to satisfy the moment condition $E(U)=0 \wedge E(|U|)=1$ (Machado and Silva, 2019). Equation (1) implies that the conditional quantile$\tau$ is given by Equation (2):

$$
Q_{Y}\left(\tau \mid X_{i t}\right)=\left(a_{i}+\delta_{i} q(\tau)\right)+X_{i t}^{\prime} \beta+Z_{i t}^{\prime} \gamma q(\tau)
$$

, with $q(\tau)=F_{U}^{-1}(\tau)$, where $F_{U}$ is the distribution function of $\mathrm{U}$. The aforementioned authors propose a recursive estimation method, based on a set of moment conditions, which is computationally simple and fast and does not require the use simulations that would render its widespread adoption difficult (e.g. Powell, 2016). They also prove that the resulting estimates are consistent and asymptotically normal.

After computing the estimates, the marginal effect of the explanatory variable $l$ on quantile $\tau$ of the dependent variable can be retrieved from Equation (3):

$$
\beta_{l}(\tau \mid X)=\beta_{l}+\frac{\partial Z^{\prime}}{\partial X_{l}} \gamma q(\tau),
$$

The Quantile via Moments model will be used, and their results will be compared with those form a Pooled OLS and Robust model estimators. The Pooled model will be used as a benchmark. These two estimators were used in order to evaluate the effect of renewable energy consumption on outdoor air pollution death rate, as well as identify if this consumption also mitigates the emissions of $\mathrm{CO} 2$. Therefore, before the realisation of Quantile via Moments model, it is necessary to verify the proprieties of variables that will be used in this study, which includes, check the normality, the presence of multicollinearity, and fixed or random effects. Consequently, the first tests that need to be applied before the regressions are:

(i) Shapiro-Wilk and Shapiro-Francia test for normality (Royston, 1983). This test verifies the normality for the model. The null hypothesis of this test is the presence of normality;

(ii) Skewness and Kurtosis test for normality (D'Agostino et al., 1990). This test checks the normality based on skewness and another based on kurtosis and then combines the two tests into an overall test statistic. The null hypothesis of this test is that the data is normally distributed;

(iii) Variance Inflation Factor (VIF) test, to verify if variables are multicollinear (Belsley et al., 1980);

(iv) Cross-sectional dependence (CSD) test to identify the presence of cross-sectional dependence (CSD) in the panel's data (Pesaran, 2004);

(v) Panel Unit Root test (CIPS) to verify the presence of unit roots in the variables(Pesaran, 2007); 
(vi) Hausman test to identify heterogeneity, i.e., whether the panel has random effects (RE) or fixed effects (F.E.). tests, such as:

Indeed, after the Quantile via Moments regression model, it is required to apply some post-estimation

(i) Breusch-Pagan / Cook-Weisberg test for heteroskedasticity (Breusch-Pagan, 1979; Cook-Weisberg, 1983). The null hypothesis of this test is the presence of homoscedasticity ${ }^{(1)}$;

(ii) Wald test (Agresti, 1990) to test the global significance of the estimated models. The null hypothesis of the Wald test is that all the coefficients are equal to zero.

These two post-estimation tests need to be applied to verify the presence of heteroscedasticity in the models. Furthermore, the estimation and testing procedures are accomplished using Stata 15.0.

\subsection{Data}

This study used annual data that was collected from 1990 to 2016 of nineteen countries from the LAC region (e.g., Argentina, Bolivia, Brazil, Chile, Colombia, Costa Rica, Dominican Republic, Ecuador, El Salvador, Guatemala, Haiti, Jamaica, Mexico, Nicaragua, Panama, Paraguay, Peru, Uruguay, and Venezuela (R.B.)). Then, the use of time-span between 1990 to 2016 is attributable to the availability of data starting in 1990 for the variable Outdoor air pollution death rates (deaths per 100,000) at Our World in Data (2020). The availability of data until 2016 for the variables carbon dioxide emissions in kilotons $(\mathrm{Kt})$ per capita, consumption of fossil and renewable energy in ( $\mathrm{kWh}$ ) per capita at World Bank Data Open (2020) for in all countries selected. Indeed, this unavailability of data up to 2016 for the variables carbon dioxide emissions in kilotons (Kt) per capita, consumption of fossil and renewable energy in $(\mathrm{kWh})$ per capita do not allow us to extend our database.

This group of countries from the LAC region due to several reasons: (a) the region has been registering an increase in air pollution levels in the last thirty years; (b) the region has experienced a rapid process of economic development caused by economic growth that encouraged the increase of urban population and consequently the consumption of fossils in the region and, consequently, the air pollution levels as mentioned before and the outdoor air pollution death rate; (c) the countries from the LAC region have registered a rapid consumption of renewable energy sources encouraged by the process of economic development, urban population growth, and environmental concern in the region; and (d) the existence of a complete database was the main criteria for choosing these countries from the LAC region. The variables used to perform this investigation are:

Table 1. Description of variables

Description of variables
Definition

Notes (1): The Breusch-Pagan / Cook-Weisberg test for heteroskedasticity can be apply only in the Pooled OLS estimator. 
Consumption of renewable energy from biomass,

hydropower, solar, photovoltaic, wind, wave and waste in ( $\mathrm{kWh}$ per capita)

RENE CONSU

Consumption of fossil fuels from oil, gas and coal sources in ( $\mathrm{kWh}$ per capita)

World Bank Open Data (2020)

FOSSIL CONSU

Urbanisation rate, which refers to people living in

urban areas as defined by national statistical offices

World Bank Open Data (2020)

URBA

The variables GDP_PC, CO2, RENE_CONSU, and FOSSIL_CONSU, were transformed into per capita values with the total population of each cross. The per capita value allows disparities to be controlled for population growth over time and within countries (Koengkan et al., 2020). Moreover, the option for using GDP in constant LCU instead of constant U.S. dollars attenuates the influence of both inflation (otherwise present in the variables of the model) and the deviation of exchange rates from their fundamentals. Indeed, it is necessary to consider that the exchange rates often deviate from their long-run fundamental equilibrium for extended periods (Santiago et al., 2019).

Additionally, the GDP in constant U.S. dollars was tested on the initial models and presented results slightly different from when constant LCU was used. Table 2 shows the summary statistics of variables.

Table 2. Descriptive statistics

\begin{tabular}{lccccc}
\hline \multirow{2}{*}{ Variables } & \multicolumn{5}{c}{ Descriptive Statistics } \\
\cline { 2 - 6 } \multicolumn{1}{c}{ Obs. } & Mean & Std.-Dev. & Min. & Max. \\
\hline LnOAPDR & 513 & 3.2677 & 0.3709 & 2.4989 & 4.4220 \\
CO2 & 513 & 11.1120 & 2.9185 & 7.2408 & 17.1658 \\
LnRENE_CONSU & 513 & 3.4413 & 5.5905 & 0.4766 & 36.0916 \\
LnFOSSIL_CONSU & 513 & 10.2061 & 0.8778 & 6.4093 & 12.0487 \\
LnURBA & 513 & 11.2782 & 0.9233 & 8.6280 & 13.4712 \\
\hline
\end{tabular}

Notes: (Ln) denote variables in the natural logarithms; Obs. denotes the number of observations in the model; Std.-Dev. denotes the Standard Deviation; Min. and Max. denote Minimum and Maximum, respectively; the command sum of Stata was used.

Moreover, we should stress that they are already in their natural logarithms (see prefix "Ln"). All variables are updated every three months. This is good practice to make the investigation updated and consistent.

\section{Empirical results}

This Section will present the empirical results of the preliminary and post-estimation tests as well as the outcomes of Pooled and Quantile via Moment estimators. Then, with the purpose of to check the normality of each model, the Shapiro-Wilk W-test for normal data was used to test the residuals of Pooled regression (e.g., Resid_OAPDR and Resid_CO2). In Table 3, we can see the results of the Shapiro-Wilk W-test for normal data for two models that will be estimated. 
Table 3. Shapiro-Wilk W-test for normal data

\begin{tabular}{lccccc}
\hline \multicolumn{1}{c}{ Variables } & Obs. & W & V & Z & Prob $>\mathbf{Z}$ \\
\hline Resid_OAPDR & 513 & 0.9171 & 28.526 & 8.064 & 0.0000 \\
Resid_CO2 & 513 & 0.8241 & 60.560 & 9.876 & 0.0000 \\
\hline
\end{tabular}

Notes: The command sktest of Stata was used.

The results of the Shapiro-Wilk W-test for normal data lead to a rejection of the null hypothesis of normality for the models OAPDR and CO2. Indeed, after the normality data test, it is required to apply the Skewness and Kurtosis test with the purpose to also identify the normality of residual of models from Pooled regression (e.g., Resid_OAPDR and Resid_CO2). The results of Table 3. Skewness/Kurtosis tests for Normality also indicate to reject the null hypothesis for two models (see Table 4).

Table 4. Skewness/Kurtosis tests for Normality

\begin{tabular}{lccccc}
\multicolumn{1}{c}{ Variables } & Obs. & Pr(Skewness) & Pr(Kurtosis) & adj chi2(2) & Prob $>$ Chi2 \\
\hline Resid_OAPDR & 513 & 0.0000 & 0.0000 & n.a. & 0.0000 \\
Resid_CO2 & 513 & 0.0000 & 0.0000 & n.a. & 0.0000 \\
\hline
\end{tabular}

Notes: The command sktest of Stata was used; n.a., denotes not available.

Moreover, the outcomes of these two tests constitute additional support for the adequacy of using the quantile regression (Afonso et al., 2019). Subsequently, the tests of normality, the VIF test that informs on the presence of multicollinearity needs to be computed. In Table 5, we can see the results of VIF-test for two models that will be estimated.

Table 5. VIF-test

\begin{tabular}{lllc}
\hline \multicolumn{1}{c}{ Variables } & VIF & 1/VIF & Mean VIF \\
\hline LnGDP_PC & OAPDR & & \\
CO2 & 1.15 & 0.8732 & 2.62 \\
LnRENE_CONSU & 3.57 & 0.2804 & \\
LnFOSSIL_CONSU & 2.32 & 0.4305 & \\
LnURBA & 3.61 & 0.2772 & \\
\hline & 2.46 & 0.4068 & 1.66 \\
\hline LnGDP_PC & 1.10 & 0.9053 & \\
LnRENE_CONSU & 1.64 & 0.6109 & \\
LnFOSSIL_CONSU & 1.75 & 0.5726 & \\
LnURBA & 2.16 & 0.4630 & \\
\hline
\end{tabular}

Notes: (Ln) denotes variables in the natural logarithms.

The results of VIF-test indicate the presence of low multicollinearity in the estimation of each model (e.g., OAPDR and CO2), where the VIF and mean VIF values are lower than the usually accepted by the benchmark of 10 , in the case of the VIF values, and 6 in the case of the mean VIF values. Moreover, to identify the presence of cross-sectional dependence (CSD) in the panel's data, the CSD-test was also used. The null hypothesis of this test is the presence of cross-section independence $\mathrm{CD} \sim \mathrm{N}(0,1)$. The results of CSD-test indicate that variables such as LnGDP_PC, CO2, LnRENE_CONSU, LnFOSSIL_CONSU, and LnURBA have the presence of cross-section dependence (see Table 6).

Table 6. Pesaran CD-test

\begin{tabular}{lccccc}
\multicolumn{1}{c}{ Variables } & CD-test & \multicolumn{2}{c}{ p-value } & Corr & Abs (corr) \\
\hline LnOAPDR & 0.24 & 0.814 & & 0.003 & 0.165 \\
\hline LnGDP_PC & 54.91 & 0.000 & $* * *$ & 0.808 & 0.808 \\
\hline CO2 & 32.49 & 0.000 & $* * *$ & 0.478 & 0.573 \\
\hline LnRENE_CONSU & 17.65 & 0.000 & $* * *$ & 0.260 & 0.462 \\
\hline LnFOSSIL_CONSU & 53.27 & 0.000 & $* * *$ & 0.784 & 0.800 \\
\hline LnURBA & 55.97 & 0.000 & $* * *$ & 0.824 & 0.926
\end{tabular}

Notes: The Stata command $x t c d$ was used; "Ln" denotes variables in natural logarithms; *** denotes statistical significance at the $1 \%$ level. 
However, the presence of CSD in these variables can be an indication that the selected countries of this study share the same characteristics and shocks (Fuinhas et al., 2017). However, the non-presence of cross-section dependence in the variable LnOAPDR can be related to different death rates from outdoor air pollution in the LAC region, making impossible the identification of the same death rates for all countries in the region.

Nevertheless, in the presence of CSD, it is necessary to verify the order of integration of the variables that will be used. To this end, the Panel Unit Root test (CIPS) developed by Pesaran (2007) was used. The null hypothesis of the Panel Unit Root test (CIPS) is that all series have a unit root. The results from the CIPS-test (see Table 7) indicate that none of the variables seems to be $\mathrm{I}(2)$, although it shows that some are borderline between $\mathrm{I}(0)$ and I(1). Moreover, the variable LnOAPDR with, and without trend shows to be I(0) (see Table 7).

Table 7. Panel Unit Root test (CIPS-test)

\begin{tabular}{|c|c|c|c|c|c|}
\hline \multirow{3}{*}{ Variables } & \multicolumn{5}{|c|}{ Panel Unit Root test (CIPS) (Zt-bar) } \\
\hline & \multicolumn{3}{|c|}{ Without trend } & \multicolumn{2}{|c|}{ With trend } \\
\hline & Lags & & -bar & Zt-bo & \\
\hline LnOAPDR & 1 & -7.213 & $* * *$ & -5.270 & $* * *$ \\
\hline LnGDP_PC & 1 & -0.742 & & -0.073 & \\
\hline $\mathrm{CO} 2$ & 1 & -3.045 & $* * *$ & -0.353 & \\
\hline LnRENE_CONSU & 1 & -2.532 & $* * *$ & -0.631 & \\
\hline LnFOSSĪL_CONSU & 1 & -2.597 & $* * *$ & -0.940 & \\
\hline LnURBA & 1 & -0.120 & & 2.755 & \\
\hline DLnGDP_PC & 1 & -6.027 & $* * *$ & -4.595 & $* * *$ \\
\hline DLnURBA & 1 & -1.590 & $*$ & -2.261 & $* *$ \\
\hline
\end{tabular}

Notes: The Stata command multipurt was used; The null for CIPS test is: series have unit root; the lag length (1) and trend were used in this test; $* * *, * *$ and $*$ denote statistically significant at the $1 \%, 5 \%$ and $10 \%$ levels, respectively: "Ln" and "D" denote variables in natural logarithms and first differences, respectively.

Indeed, since most variables appear to be somewhere borderline between $\mathrm{I}(0)$ and $\mathrm{I}(1)$, this investigation opted not to perform the Westerlund cointegration test (Wersterlund, 2007), to identify the presence the cointegration between the variables, where this test requires that all variables are I(1). After the realisation of the panel unit root test, the next stage is to assess the presence of individual effect in each model (e.g., OAPDR and CO2). To this end, the Hausman test, comparing random (RE) and fixed effects (F.E.), was used. The null hypothesis of this test is that the difference in coefficients is not systematic, (i.e., random effects are the most suitable estimator). In Table 8, we can see the results of the Hausman test for four models that will be estimated.

Table 8. Hausman test

\begin{tabular}{cc} 
OAPDR & CO2 \\
$\operatorname{chi} 2(5)=66.23 * * *$ & $\operatorname{chi} 2(4)=139.65^{* * *}$ \\
\hline
\end{tabular}

Notes: $* * *$ denotes statistically significant at the $1 \%$ level; Hausman results for $\mathrm{H}_{0}$ : difference in coefficients not systematic; the Stata commands hausman (with the options sigmamore) was used.

The Hausman test indicates that the null hypothesis should be rejected in two models and that a fixedeffects model is the most appropriate for this analysis. After the realisation of preliminary tests, the Pooled and Quantile via Moments estimator can be made. Remembering that the Quantile via Moments is the principal methodology of this investigation, and their results will be compared with those from a Pooled OLS and Robust estimators.

Consequently, the Pooled OLS and Pooled Robust estimators will be used as a benchmark for the Quantile via Moments estimator. Indeed, the Pooled Robust was added in this estimation due to the possible presence of heteroscedasticity in the models based on visual analysis of descriptive statistics of variables. The Pooled Robust provides corrected standard errors, and consequently, the correct coefficient significant level (Afonso et al., 2019). Regarding the Quantile via Moments, the $25^{\text {th }}, 50^{\text {th }}$, and $75^{\text {th }}$ quantiles were respectively calculated with the purpose of assessing the impact of renewable energy consumption on deaths from outdoor air pollution. Indeed, both the methods that will be used do not allow to perform causalities; it only allows observing the effect at the quantiles. Table 9 shows the results of Pooled OLS and Robust, and Quantiles of OAPDR model, as well as the results of post-estimation tests (e.g., Breusch-Pagan / Cook-Weisberg test for heteroskedasticity and Wald test), to confirm the presence of heteroskedasticity in the models. Remembering that only the BreuschPagan / Cook-Weisberg test for heteroskedasticity can be applied in the Pooled OLS estimator, and the Wald test can be applied only in the Quantile via Moments estimator. 
Table 9. Estimations for outdoor air pollution death rates (OAPDR)

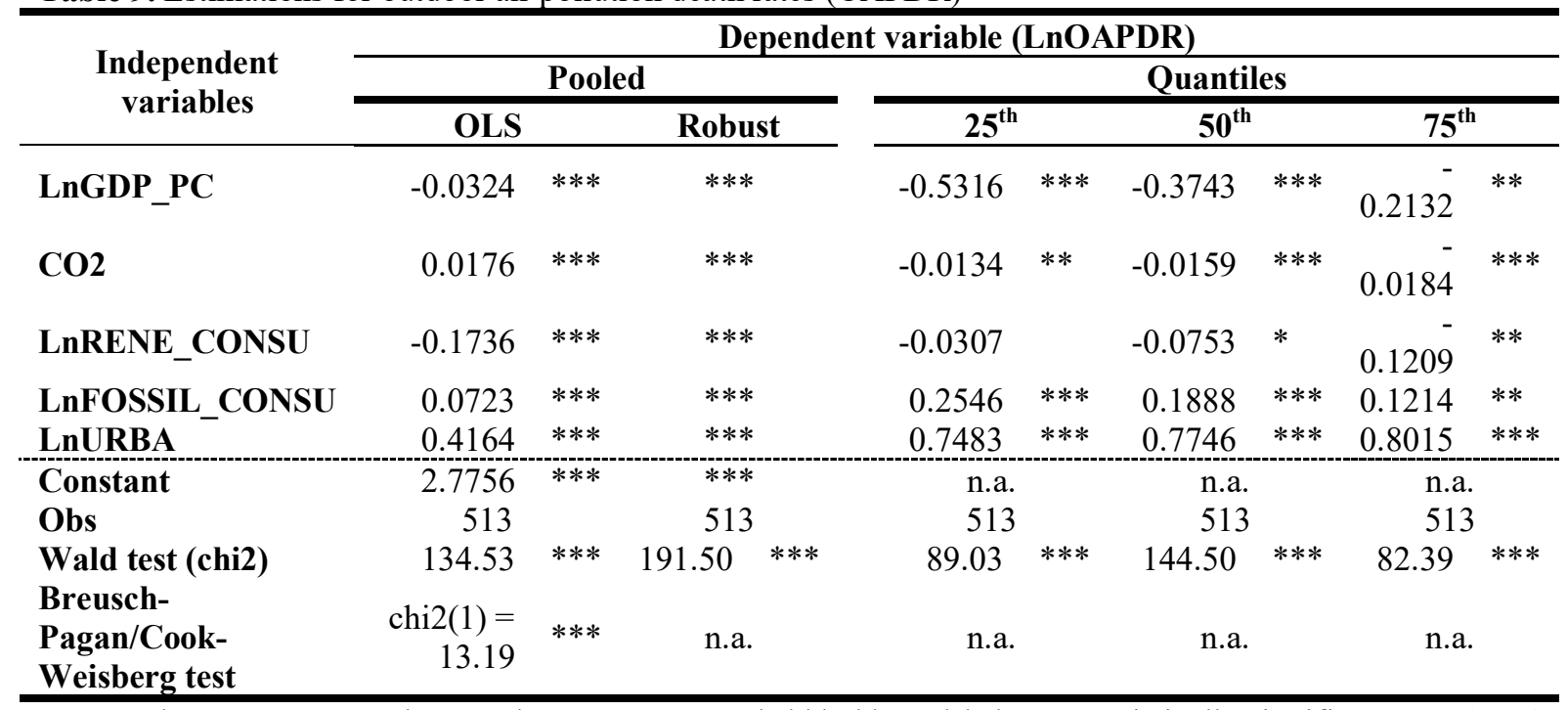

Notes: The Stata command reg and xtqreg were used; ***,**, and * denote statistically significant at $1 \%, 5 \%$ and 10\% level respectively; ( $\mathrm{Ln}$ ) denotes variables in natural logarithms. The option robust was used in OLS estimation; n.a., denotes not available.

The Pooled OLS and Robust estimators indicate that emissions of CO2, consumption of fossil fuels and urbanisation increase the deaths from outdoor air pollution, and the economic growth and the consumption of renewable energy decrease these deaths. Moreover, the results from the Pooled estimator are statistically significant at 1\% levels in the OLS and Robust estimators. The Quantile via Moments indicates that in the $25^{\text {th }}$, $50^{\text {th }}$, and $75^{\text {th }}$ quantiles the economic growth, emissions of $\mathrm{CO} 2$, decrease the deaths from outdoor air pollution, while the renewable energy consumption decrease in $50^{\text {th }}$ and $75^{\text {th }}$ quantiles. However, the consumption of fossil fuels and urbanisation increase these deaths from outdoor air pollution in the $25^{\text {th }}, 50^{\text {th }}$, and $75^{\text {th }}$ quantiles. Moreover, the results from this estimator are statistically significant at the $1 \%, 5 \%$, and $10 \%$ levels, respectively. The post-estimation tests (e.g., Breusch-Pagan / Cook-Weisberg test for heteroskedasticity and Wald test) indicates the presence of heteroscedasticity in the model. The result from the post-estimation test is an indicator that the estimations that this investigation use is adequate.

Indeed, the capacity of renewable energy and emissions of $\mathrm{CO} 2$ to decrease the deaths from outdoor air pollution can be related to the consumption of this kind of source that decreases the emissions of $\mathrm{CO} 2$ that cause these deaths. So, does the consumption of renewable energy decrease the $\mathrm{CO} 2$ emissions in Latin America and the Caribbean region? This investigation will also verify the impact of renewable energy consumption on CO2 emissions to identify this possible reduction. Table 10 shows the results of Pooled OLS and Robust, and Quantiles of CO2 model, as well as the results of post-estimation tests (e.g., Breusch-Pagan / Cook-Weisberg test for heteroskedasticity and Wald test), to confirm the presence of heteroskedasticity in the models.

Table 10. Estimations for $\mathrm{CO} 2$ emissions

\begin{tabular}{|c|c|c|c|c|c|c|c|c|c|c|}
\hline \multirow{3}{*}{$\begin{array}{l}\text { Independent } \\
\text { variables }\end{array}$} & \multicolumn{10}{|c|}{ Dependent variable (CO2) } \\
\hline & \multicolumn{4}{|c|}{ Pooled } & \multicolumn{6}{|c|}{ Quantiles } \\
\hline & OLS & & \multicolumn{2}{|c|}{ Robust } & \multicolumn{2}{|c|}{$25^{\text {th }}$} & \multicolumn{2}{|c|}{$50^{\text {th }}$} & \multicolumn{2}{|c|}{$75^{\text {th }}$} \\
\hline LnGDP_PC & 0.2045 & $* * *$ & $* * *$ & & 8.0317 & $* * *$ & 8.5633 & $* * *$ & 9.0699 & $* * *$ \\
\hline LnRENE_CONSU & -2.7934 & $* * *$ & $* * *$ & & -3.6494 & $* * *$ & -3.6071 & $* * *$ & 3.5667 & *** \\
\hline LnFOSSIL_CONSU & 4.3741 & $* * *$ & $* * *$ & & 0.9914 & $* *$ & 0.8498 & $* * *$ & 0.7148 & \\
\hline LnURBA & -7.4130 & $* * *$ & $* * *$ & & 10.3509 & $* * *$ & $10.1324^{-}$ & $* * *$ & $9.9241^{-}$ & $* * *$ \\
\hline Constant & 11.4583 & $* * *$ & $* * *$ & & n.a. & & n.a. & & n.a. & \\
\hline Obs & 513 & & 513 & & 513 & & 513 & & 513 & \\
\hline Wald test & 325.84 & $* * *$ & 68.29 & $* * *$ & 57.90 & $* * *$ & 97.74 & $* * *$ & 56.38 & $* * *$ \\
\hline $\begin{array}{l}\text { Breusch- } \\
\text { Pagan/Cook- } \\
\text { Weisberg test }\end{array}$ & $\operatorname{chi} 2(1)=765.46$ & $* * *$ & n.a. & & n.a. & & n.a. & & n.a. & \\
\hline
\end{tabular}

Notes: The Stata commands reg and xtqreg used; *** and ** denote statistically significant at the $1 \%$ and $5 \%$ levels, respectively; ( $\mathrm{Ln}$ ) denotes variables in natural logarithms; the option robust was used in OLS estimation; n.a., denotes not available. 
The Pooled OLS and Robust estimators indicate that the economic growth, consumption of fossil fuels and urbanisation increase the emissions of $\mathrm{CO} 2$. In contrast, renewable energy consumption and urbanisation mitigate these emissions as expected. Moreover, the results from the Pooled model are statistically significant at the $1 \%$ level in the OLS and Robust estimators. The Quantile via Moments indicates that in the $25^{\text {th }}, 50^{\text {th }}$, and $75^{\text {th }}$ quantiles the economic growth increases the emissions of $\mathrm{CO} 2$, while the consumption of fossil fuels increases in the 25th and 50th quantiles. However, the consumption of renewable energy and urbanisation in the $25^{\text {th }}, 50^{\text {th }}$, and $75^{\text {th }}$ quantiles decrease these emissions. Moreover, the results from this estimator are statistically significant at $1 \%$, and 5\%, level. Additionally, the post-estimation tests (e.g., Breusch-Pagan / Cook-Weisberg test for heteroskedasticity and Wald test) indicating the presence of heteroscedasticity in the model. The result from the post-estimation test is an indicator that the estimations that this investigation use is adequate.

\section{Discussion}

The economic activity requires the use of physical resources that exert pressure on environmental conditions that end several types of pollution. Among the pollutants generated by the use of resources, the ones that materialise in degrading air quality have an impact on the health of human beings that leads to lowering life quality, and in extreme cases to premature death.

The literature linking economic activity and air pollution have been focused on a nonlinear relationship, like EKC, to explain the relationship between GDP and air pollution. This bulk of literature was based on a particular conception of how the economic growth evolves and how the level of economic activity relates itself with pollutions in two ways. The first relates the absolute values of economic activity and the level of pollution. The second, relates the same former variables, in per capita values. The two approaches produce what can seem to be contradictory results. Indeed, we can see pollution growing but pollution per capita decreasing.

The classical EKC approach is rooted in a perspective in which the early stages of economic development lead to higher levels of pollution that are followed by concerns about environmental preservation as societies become rich (and able to back the costs of mitigating environmental deterioration) that materialises in pollution declines. In our analysis, we were more interested in capturing another effect, the one that results from technical progress. To do that, we use quantile regression for panel data, in a group of countries that share similar characteristics, the LAC countries.

Our results are more consistent with the results achieved to LAC region that support the presence of an EKC hypothesis (Hanif, 2017; Sapkota and Bastola, 2017), than with the ones that report a monotonically positive association between economic growth and $\mathrm{CO}_{2}$ emissions (Pablo-Romero and Jesus, 2016; Jardón et al., 2016; Van-Ruijven et al., 2016). The negative sign coefficient for LNGPD_PC on OAPDR (see Table 9), can be explained by the presence of better health systems in richer countries, which contributes to mitigating the mortality rate.

The economic growth can contribute to reducing the death rates because it allows the financing of better health systems. Indeed, this effect of economic growth on the improvement in the health systems can lower the mortality rate from air pollution. The LAC region had experienced several transformations in the later decades that can mitigate the air pollution death rates.

The LAC region improved its health system throughout the period from 1989 to 2014. This improvement was especially intense during the "commodities boom" that had materialised from 2004 to 2014. The economic growth throughout that period had provided enough budgetary flexibility and fiscal space to change the structure of their approach to public health. Indeed, that had enabled the realisation of supply-side policies that strengthened the health systems, allowing the implementation of the universal health coverage, and expanded access of health system to the most vulnerable populations (Koengkan and Fuinhas, 2020a; Atun et al., 2015). The period from 1989 to 1992 have also seen macroeconomic and social reforms that further improved health systems in several countries (e.g., Argentina, Brazil, Chile, Colombia, Mexico, Peru, and Uruguay) in the LAC region (Koengkan and Fuinhas, 2020b). These macroeconomic reforms permitted the implementation of conditional cash transfer schemes that expanded the access to health, education, and diminish the poverty and malnutrition (Koengkan and Fuinhas, 2020a; Atun et al., 2015).

Regarding the negative effect of $\mathrm{CO}_{2}$ emissions on OAPDR (see Table 9), it can be simply related to renewable energies, i.e. the effect we want to identify. If renewables decrease the OAPDR that is caused by $\mathrm{CO}_{2}$ emissions (a proxy of air pollution), then it is expected that there will be a decrease in $\mathrm{CO}_{2}$ emissions (see Table 10). One possibility is because the effect of $\mathrm{CO}_{2}$ emissions is negative on OAPDR, and renewables sources on $\mathrm{CO}_{2}$ emissions (see Figure 11). A feasible explanation for the negative sign of the $\mathrm{CO} 2$ coefficient is the possibility that more severe sources of pollution for public health are being replaced by others that emit CO2. This pollutant is less aggressive to health than other toxic gases. Nevertheless, this hypothesis requires further investigation. 


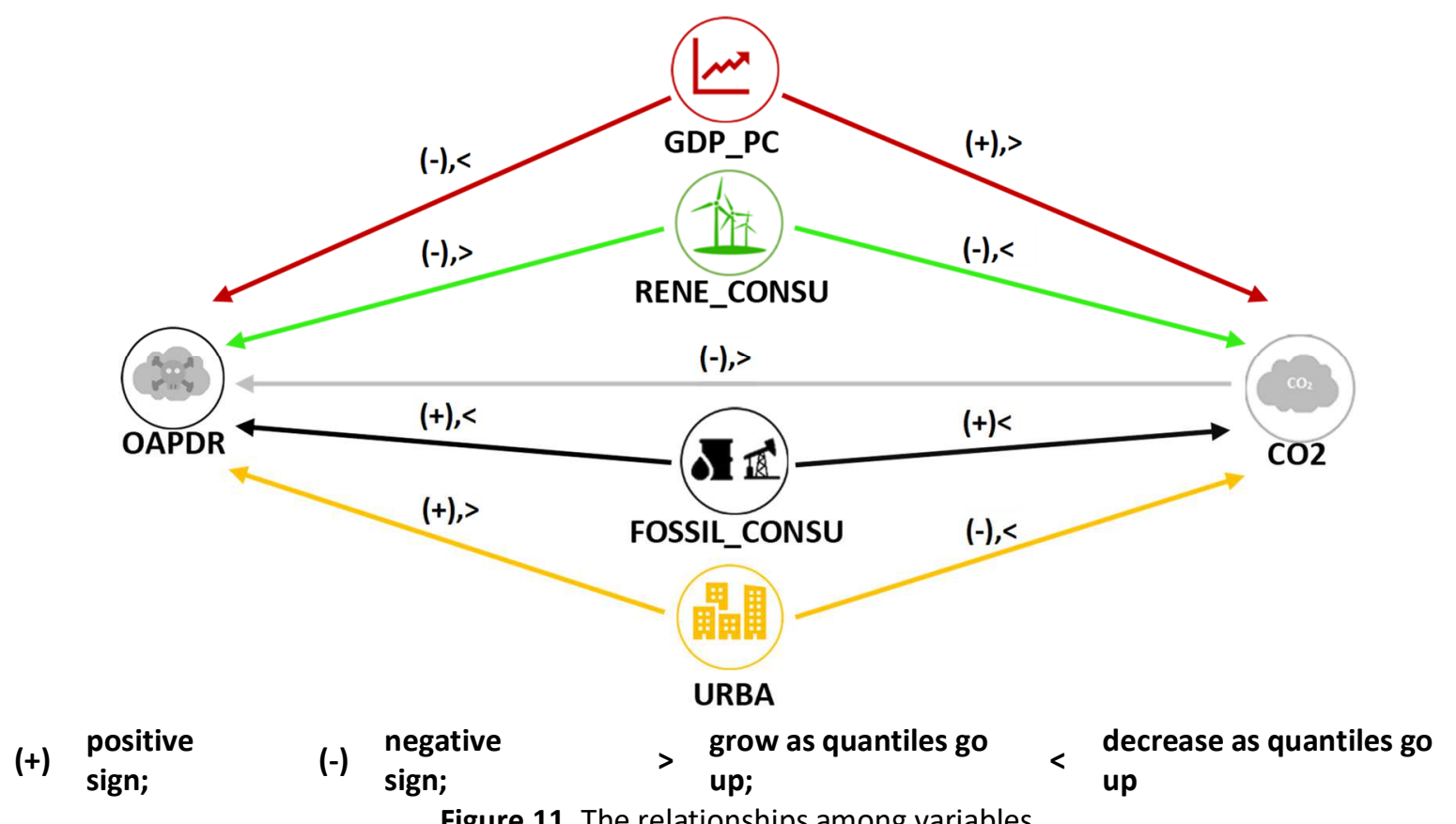

Figure 11. The relationships among variables

The positive coefficient of LNGPD_PC on CO2 (see Table 10) is compatible with several studies on the "Environmental Kuznets curve" for Latin American countries. The increasing population living in large cities in the LAC region has imposed a toll on the deaths from air pollution. Romieu et al. (1990) support that it is due to the rapid process of urbanisation during the $20^{\text {th }}$ century.

LAC countries are among the most urbanised in the developing countries. The total urban population has evolved from 68 million dwellers in 1950 to 466 million by 2000, i.e. an increase of more than $400 \%$ in five decades. The LAC's region has four large urban areas with more than 2 million dwellers such as Sao Paulo and Rio de Janeiro (Brazil), Mexico City (Mexico), and Bueno Aires (Argentina).

Moreover, the fast urbanisation's growth in the LAC's countries can relate to several economic reforms that stimulated the economic development in the last three decades. The introduction of new technologies in agriculture and the industrialisation's growth has led, in most Latin American countries, to economic restructuring, as the economies change from rural-based economies to industrial ones (Koengkan et al., 2019c). Therefore, one can expect that urbanisation generates air pollution that causes related deaths. Indeed, the restructuring in LAC countries led to a relationship between economic growth, urbanisation, and consumption of fossil fuels. Consequently, there was an increase in CO2 emissions and other toxic gases (Koengkan et al., 2019c).

On the renewable energy, our results for LAC countries, point to economic growth affect $\mathrm{CO} 2$ emissions in a way that can lead to an anticipation of the turning point of the EKC as suggested by Alvarez-Herranz et al. (2017). Indeed, the results are in line with most research involving this hypothesis in LAC countries (Koengkan et al., 2020; Yao et al., 2019; Koengkan et al., 2019b; Koengkan, 2018; Ito, 2017; Fuinhas et al., 2017; Özbuğday and Erbas, 2015; Robalino-López et al., 2015; Shafiei and Salim, 2014).

On the impact of air pollution on mortality, our results are in line with ones for LAC countries that report an increase in mortality (Nabizadeh et al., 2019; Pope et al., 2019; Liu et al., 2019; Gouveia and Junger, 2018; Vodonos et al., 2018; Costa et al., 2017a; Costa et al., 2017b; Bravo et al., 2016; Romieu et al., 2012; O'Neill et al. 2008; Gouveia and Fletcher, 2000).

The negative coefficient for LNURBA on CO2 (see Table 10) can also be explained by the fact that rural populations resort more to burning wood and other biofuels for heating and cooking.

A second noteworthy result is related to the negative sign for the effect of urbanisation on $\mathrm{CO}_{2}$ emissions (see Table 10). Could this negative effect be related to changes in the energy matrix and the transport network of engineering (e.g. construction) that emit fewer pollutants? Or simply is the resulting of stagnation of large urban centres? Nevertheless, if there is this negative effect on $\mathrm{CO}_{2}$ emissions, should not it also be negative on the rate of deaths from outdoor pollution? Can this negative signal be related to the variable OAPDR is based only on large urban centres of LAC countries?

\section{Conclusions and policy implications}

The impact of renewable energy consumption on reducing the outdoor air pollution death rate was researched for nineteen Latin America \& the Caribbean region, from 1990 to 2016. There are theoretical fundamentals that strongly suggest a non-linear relationship between energy consumption (renewable and fossil), economic growth and urbanisation with the outdoor air pollution death rates. The econometric technique of 
Quantile Regression for Panel Data (Quantile via Moments) was used to cope with this expected (and confirmed) non-linear relationship.

The main research question of this investigation (Does renewable energy consumption decrease the air pollution diseases death in Latin America \& the Caribbean countries?) has an affirmative answer.

The secondary research question (What is the impact of renewable energy consumption on $\mathrm{CO} 2$ emissions?) that broadly results from the deepening of the main question indicates that the consumption of renewable energy decreases de $\mathrm{CO} 2$ emissions. Indeed, renewable energy can mitigate or even reduces the diseases and deaths provoked by air pollution in Latin America \& the Caribbean region. This capacity can be related to its capacity to reduce the consumption of fossil fuels, and, consequently, the $\mathrm{CO} 2$ emissions that contribute to many environmental problems harming human health. That includes poor air quality and climate change.

The results support that economic growth contributes to the decrease in outdoor air pollution death rates, but this effect is more intense if the deaths have not yet reached very high levels. In other words, when there is already a high prevalence of outdoor air pollution death rates, economic growth is less effective in reducing deaths.

Consumption of renewable energy plays a crucial role in reducing outdoor air pollution death rates. This effect is most substantial when the outdoor air pollution death rates are high. The consumption of fossil fuels and urbanisation aggravate outdoor air pollution death rates. The effect here is divergent, fossil fuels diminish its effect, but urbanisation intensifies the same.

In short, our results show that economic growth and fossil fuel consumption are positively related to $\mathrm{CO} 2$ emissions, while renewable energy consumption bears a negative relationship with it. Furthermore, fossil fuel consumption has a positive impact on the mortality rate and economic growth a negative one. Curiously, the negative effect of renewable energy consumption on the mortality rate is only observable on the right tail of its distribution.

Public policymakers must focus on intensifying the energy transition from fossil fuels to renewable energies. The estimations revealed two vias that can be pursued to reduce the mortality that is caused by outdoor air pollution. Firstly, a direct decrease in deaths resulting from the increasing consumption of renewable energies. Second, an indirect decrease in deaths resulting from the finding that the increase in the consumption of renewable energies more often than not implies a decrease in the consumption of energy from fossil energy sources. The research also concludes that the phenomenon of increasing urbanisation is a point where the action of public policymakers is decisive for the reduction of outdoor air pollution death rates. In this case, the question is not to reduce the level of urbanisation, but to act on the urbanisation's "quality". In other words, intervene to make cities healthier for human beings.

Finally, the investigation raises an issue that requires further investigation. Why are $\mathrm{CO} 2$ emissions contributing to a decrease in outdoor air pollution death rates? This result cannot be read so directly. $\mathrm{CO} 2$ emissions cannot be beneficial for human health! Indeed, the question requires an indirect approach. What source of pollution, which has a strong effect on outdoor air pollution death rates, is being replaced by one that generates $\mathrm{CO} 2$ emissions? In this case, the replacement of pollution sources can result in an "apparent" beneficial effect of $\mathrm{CO} 2$ emissions on the outdoor air pollution death rates.

\section{References}

Afonso T.L., Marques A.C., Fuinhas J.A., (2019). Energy-growth nexus and economic development: a quantile regression for panel data. The Extended Energy-Growth Nexus, p. 1-25. doi: 10.1016/b978-0-12-8157190.00001-2.

Aghahosseini A., Bogdanov D., Barbosa L.S.N.S., Breyer C., (2019). Analysing the feasibility of powering the Americas with renewable energy and inter-regional grid interconnections by 2030 . Renewable and Sustainable Energy Reviews, 105:187-205. https://doi.org/10.1016/j.rser.2019.01.046.

Agresti A., (1990). Categorical Data Analysis. John Wiley and Sons, New York. ISBN 0-471-36093-7.

Aizenman J., (2005). Financial Liberalizations in Latin America in the 1990s: A reassessment. NBER working paper series, 11145:1-30. URL: https://www.nber.org/papers/w11145.

Alvarez-Herranz, A., Balsalobre-Lorente, D., Shahbaz, M., Cantos, J.M., (2017). Energy innovation and renewable energy consumption in the correction of air pollution levels. Energy Policy, 105:386-397. https://doi.org/10.1016/j.enpol.2017.03.009.

Apergis N., Payne J.E., Menyah K., Wolde-Rufael Y., (2010). On the causal dynamics between emissions, nuclear energy, renewable energy, and economic growth. Ecological Economics, 69(11):2255-2260. https://doi.org/10.1016/j.ecolecon.2010.06.014.

Atun R., Andrade L.O.M., Almeida G., Cotlear D., Dmytraczenko T., Frenz P., Garcia P., Dantés O.G., Knaul F.M., Muntaner C., Paula J.B., Rígoli F., Serrate C.-F., Wagstaff A., (2015). Health-system reform and universal health coverage in Latin America. The Lancet 385(9974):1230-1247. doi: https://doi.org/10.1016/S0140-6736(14)61646-9. 
Balakrishnan K. et al., (2019). The impact of air pollution on deaths, disease burden, and life expectancy across the states of India: the Global Burden of Disease Study 2017. Lancet Planet Health, 3(1):e26-e39. https://doi.org/10.1016/S2542-5196(18)30261-4.

Barbosa L.S.N.S., Bogdanov D., Vainikka P., Breyer C., (2017). Hydro, wind and solar power as a base for a $100 \%$ renewable energy supply for South and Central America. PLoS One 12(3) https://doi.org/10.1371/journal.pone.0173820.

Bayat R., Ashrafi K., Motlagh M.S., Hassanvand M.S., Daroudi R., Fink G., Künzli N., (2019). Health impact and related cost of ambient air pollution in Tehran. Environmental Research, 176:108547. https://doi.org/10.1016/j.envres.2019.108547.

Becken S., Jin X., Chen Z., Gao J., (2016). Urban air pollution in China: risk perceptions and destination image. Journal of Sustainable Tourism, 25(1):130-147. https://doi.org/10.1080/09669582.2016.1177067.

Belsley D.A., Kuh E., Welsch R.E., (1980). Regression Diagnostics: Identifying Influential Data and Sources of Collinearity. New York: Wiley. doi: 10.1002/0471725153.

Bharadwaj P., Gibson M., Zivin J.G., Neilson C., (2017). Gray Matters: Fetal Pollution Exposure and Human Capital Formation. Journal of the Association of Environmental and Resource Economists, 4(2):505-542. https://doi.org/10.1086/691591.

Bilgili, F., Koçak, E., Bulut, Ü., (2016). The dynamic impact of renewable energy consumption on CO2 emissions: A revisited Environmental Kuznets Curve approach. Renewable and Sustainable Energy Reviews, 54, 838-845. https://doi.org/10.1016/j.rser.2015.10.080.

BloombergNEF. (2020). Latin America Hit New Clean Energy Investment Record, 2019. URL:https://about.bnef.com/blog/latin-america-hit-new-clean-energy-investment-record-2019/.

Bravo M.A., Son J., De Freitas C.U., Gouveia N., Bell, M.L., (2016). Air pollution and mortality in São Paulo, Brazil: Effects of multiple pollutants and analysis of susceptible populations. Journal of Exposure Science and Environmental Epidemiology, 26(2):150-161. https://doi.org/10.1038/jes.2014.90.

Breusch T.S., Pagan A.R., (1979). A simple test for heteroscedasticity and random coefficient variation. Econometrica 47:1287-1294. doi: 10.2307/1911963.

Brønnum-Hansena H., Bender A.M., Andersen Z. J., Sørensen J., Bønløkke J.H., Boshuizen H., Becker T., Diderichsen F., Loft S., (2018). Assessment of impact of traffic-related air pollution on morbidity and mortality in Copenhagen Municipality and the health gain of reduced exposure. Environment International 121(Part 1):973-980. https://doi.org/10.1016/j.envint.2018.09.050.

Buonocore J.J., Luckow P., Norris G., Spengler J.D., Biewald B., Fisher J., Levy J.I., (2015). Health and climate benefits of different energy-efficiency and renewable energy choices. Nature Climate Change 6(1):100105. doi: $10.1038 /$ nclimate2771.

Canay I.A., (2011). A Simple Approach to Quantile Regression for Panel Data. The Econometrics Journal, 14:368386. doi: 10.1111/j.1368-423X.2011.00349.x.

Carneiro R.M., (2012). Commodities, choques externos e crescimento: reflexões sobre a América Latina. CEPAL, 117:1-47. ISSN: 1680-8843. URL: http://www.eco.unicamp.br/cecon/images/arquivos/observatorio/Commodities_choques_externos_cresc imento.pdf.

Cohen A.J., Brauer M., Burnett R., et al., (2017). Estimates and 25-year trends of the global burden of disease attributable to ambient air pollution: an analysis of data from the Global Burden of Diseases Study 2015. Lancet, 389: 1907-18. https://doi.org/10.1016/S0140-6736(17)30505-6.

Cook R.D., Weisberg S., (1983). Diagnostics for heteroscedasticity in regression. Biometrika 70:1-10. doi: $10.2307 / 2335938$.

Costa A.F., Hoek G., Brunekreef B., Ponce de Leon A.C.M., (2017a). Effects of NO2 exposure on daily mortality in São Paulo, Brazil. Environmental Research, 159(2):539-544. https://doi.org/10.1016/j.envres.2017.08.041.

Costa A.F., Hoek G., Brunekreef B., Ponce de Leon A.C.M., (2017b). Air pollution and deaths among elderly residents of São Paulo, Brazil: An analysis of mortality displacement. Environmental Health Perspectives, 125(3):349-354. https://doi.org/10.1289/EHP98.

D'Agostino R. B., Belanger A. J., D'Agostino Jr. R.B., (1990). A suggestion for using powerful and informative tests of normality. American Statistician, 44:316-321. doi: 10.2307/2684359. 
Environmental Protection Agency (EPA). (2018). Quantifying the Multiple Benefits of Energy Efficiency and Renewable Energy. The Multiple Benefits of Energy Efficiency and Renewable Energy. EPA Publication, $1-17$.

FGV Energia. (2016). A comparative analysis of energy transition in Latin America and Europe, p. 1-72. URL: http://www.fgv.br/fgvenergia/paper_kas-fgv_ingles/files/assets/common/downloads/Paper_KASFGV Ingl Web.pdf.

Fuinhas J.A., Marques A.C., Koengkan M., (2017). Are renewable energy policies upsetting carbon dioxide emissions? The case of Latin America countries. Environmental Science and Pollution Research, 24(17):15044-15054. https://doi.org/10.1007/s11356-017-9109-z.

Gouveia N., Fletcher T., (2000). Time series analysis of air pollution and mortality: Effects by cause, age and socioeconomic status. Journal of Epidemiology and Community Health, 54(10):750-755. https://doi.org/10.1136/jech.54.10.750.

Gouveia N., Junger W.L., Romieu, I., Cifuentes, L.A., De Leon A.P., Vera J., Strappa V., Hurtado-Díaz M., Miranda-Soberanis V., Rojas-Bracho L., Carbajal-Arroyo L., Tzintzun-Cervantes G. (2018). Effects of air pollution on infant and children respiratory mortality in four large Latin-American cities. Environmental Pollution, 232:385-391. https://doi.org/10.1016/j.envpol.2017.08.125.

Greenstone M., (2004). Did the Clean Air Act cause the remarkable decline in sulfur dioxide concentrations? Journal of Environmental Economics and Management, 47(3):585-611. https://doi.org/10.1016/j.jeem.2003.12.001.

Griffith-Jones S.S., Andrade S., Griffth-Jones E., (2017). Investment in renewable energy, fossil fuel prices and policy implications for Latin America and the Caribbean. ECLAC, 1033-1046. https://doi.org/10.1017/CBO9781107415324.004.

Grossman G., Krueger A., (1991). Environmental Impacts of a North American Free Trade Agreement. National Bureau of Economic Research, 3914. https://doi.org/10.3386/w3914.

Hanif I., (2017). Economics-energy-environment nexus in Latin America and the Caribbean. Energy, 141, 170178. https://doi.org/10.1016/j.energy.2017.09.054.

Hove S., Tursoy T., (2019). An investigation of the environmental Kuznets curve in emerging economies. Journal of Cleaner Production, 236:117628. https://doi.org/10.1016/j.jclepro.2019.117628.

Institute for Health Metrics and Evaluation (IHME). (2018). Global, regional, and national comparative risk assessment of 84 behavioural, environmental and occupational, and metabolic risks or clusters of risks for 195 countries and territories, 1990-2017: a systematic analysis for the Global Burden of Disease Study 2017. URL: http://www.healthdata.org/research-article/global-regional-and-national-comparative-riskassessment-84-behavioral-0.

International Council on Clean Transportation, (2010). Overview of China's Vehicle Emission Control Program: Past Successes and Prospects. http://www.theicct.org/sites/default/files/publications/Retrosp_final_bilingual.pdf.

Ito K., (2017). CO2 emissions, renewable and non-renewable energy consumption, and economic growth: Evidence from panel data for developing countries. International Economics, 151:1-6. https://doi.org/10.1016/j.inteco.2017.02.001.

Jardón A., Kuik O., Tol R.S.J., (2017). Economic growth and carbon dioxide emissions: An analysis of Latin America and the Caribbean. Atmosfera, 30(2):87-100. https://doi.org/10.20937/ATM.2017.30.02.02.

Koengkan M., (2018). The decline of environmental degradation by renewable energy consumption in the MERCOSUR countries: an approach with ARDL modeling. Environment Systems and Decisions, 38(3):415-425. https://doi.org/10.1007/s10669-018-9671-z.

Koengkan M., Fuinhas J.A., (2020a). Exploring the effect of the renewable energy transition on CO2 emissions of Latin American \& Caribbean countries. International Journal of Sustainable Energy, p.1-24. doi: https://doi.org/10.1080/14786451.2020.1731511.

Koengkan M., Fuinhas J.A., (2020b). The interactions between renewable energy consumption and economic growth in the Mercosur countries. International Journal of Sustainable Energy, 39(6): 594-614. doi: https://doi.org/10.1080/14786451.2020.1732978.

Koengkan M., Fuinhas J.A., Marques A.C., (2019c). The effect of fiscal and financial incentive policies for renewable energy on $\mathrm{CO} 2$ emissions: the case for the Latin American region. In The Extended EnergyGrowth Nexus. Elsevier Inc. https://doi.org/10.1016/b978-0-12-815719-0.00005-x. 
Koengkan M., Fuinhas J.A., Santiago R., (2020). The relationship between CO2 emissions, renewable and nonrenewable energy consumption, economic growth, and urbanisation in the Southern Common Market. Journal of Environmental Economics and Policy, p. 1-20. doi: 10.1080/21606544.2019.1702902.

Koengkan M., Fuinhas J.A., Santiago, R., (2019a). Asymmetric impacts of globalisation on CO2 emissions of countries in Latin America and the Caribbean. Environment Systems and Decisions, p.1-13. doi:10.1007/s10669-019-09752-0.

Koengkan M., Fuinhas J.A., Vieira I., (2019b) Effects of financial openness on renewable energy investments expansion in Latin American countries. Journal of Sustainable Finance \& Investment, 10(1):65-82. doi: https://doi.org/10.1080/20430795.2019.1665379.

Koengkan M., Poveda Y.E., Fuinhas J.A., (2019c). Globalisation as a motor of renewable energy development in Latin America countries. GeoJournal, p.1-12. doi: 10.1007/s10708-01910042-0.

Koenker R., (2004). Quantile Regression for Longitudinal Data. Journal of Multivariate Analysis, 91:74-89. doi: 10.1016/j.jmva.2004.05.006.

Koenker, R., (2005). Quantile Regression (Econometric Society Monographs). Cambridge: Cambridge University Press. doi:10.1017/CBO9780511754098.

Landrigan P.J., Fuller R., Acosta N.J.R., et al., (2018). The Lancet Commission on pollution and health. Lancet, 391:462-512. https://doi.org/10.1016/S0140-6736(17)32345-0.

Li P., Lu Y., Wang J., (2020). The effects of fuel standards on air pollution: Evidence from China. Journal of Development Economics, 146(2020):102488. https://doi.org/10.1016/j.jdeveco.2020.102488.

Liu C., Chen R., Sera F., Vicedo-Cabrera A.M., Guo Y., Tong S., Coelho M.S.Z.S., Saldiva P.H.N., Lavigne E., Matus P., Ortega N.V., Garcia S. O., Pascal M., Stafoggia M., Scortichini M., Hashizume M., Honda Y., Hurtado-Díaz M., Cruz J., Kan H., (2019). Ambient particulate air pollution and daily mortality in 652 cities. New England Journal of Medicine, 381(8):705-715. https://doi.org/10.1056/NEJMoa1817364.

Machado J.A.F., Silva JMCS, (2019). Quantiles via Moments. Journal of Econometrics, forthcoming. doi: 10.1016/j.jeconom.2019.04.009Get.

Nabizadeh R., Yousefian F., Moghadam V.K., Hadei M., (2019). Characteristics of cohort studies of long-term exposure to PM2.5: a systematic review. Environmental Science and Pollution Research, 26(30):3075530771. https://doi.org/10.1007/s11356-019-06382-6.

Nasari M.M., Szyszkowicz M., Chen H., Crouse D., Turner M.C., Jerrett M., et al., (2016). A class of non-linear exposure-response models suitable for health impact assessment applicable to large cohort studies of ambient air pollution. Air Quality, Atmosphere \& Health, 9(8),961-972. https://doi.org/10.1007/s11869016-0398-z.

O'Neill M.S., Bell M.L., Ranjit N., Cifuentes L.A., Loomis D., Gouveia N., Borja-Aburto V.H., (2008). Air pollution and mortality in Latin America: The role of education. Epidemiology, 19(6): 810-819. https://doi.org/10.1097/EDE.0b013e3181816528.

Onyedikachi O. J., (2015). Robustness of Quantile Regression to Outliers. American Journal of Applied Mathematics and Statistics, 3(2): 86-88. doi: 10.12691/ajams-3-2-8.

Özbuğday F.C., Erbas B.C., (2015). How effective are energy efficiency and renewable energy in curbing CO2 emissions in the long run? A heterogeneous panel data analysis. Energy, 82:734-745. https://doi.org/10.1016/j.energy.2015.01.084.

Pablo-Romero M.D.P., De Jesús J., (2016). Economic growth and energy consumption: The EnergyEnvironmental Kuznets Curve for Latin America and the Caribbean. Renewable and Sustainable Energy Reviews, 60:1343-1350. https://doi.org/10.1016/j.rser.2016.03.029.

Pablo-Romero M.P., Román R., Sánchez-Braza A., Yñiguez R., (2016). Renewable Energy, Emissions, and Health, Renewable Energy - Utilisation and System Integration, Wenping Cao and Yihua $\mathrm{Hu}$, IntechOpen, doi: 10.5772/61717.

Parry I.W.H., Walls M., Harrington W., (2007). Automobile Externalities and Policies. Journal of Economic Literature, 45(2):373-399. doi: 10.1257/jel.45.2.373.

Pesaran M.H., (2004). General diagnostic tests for cross-section dependence in panels. The University of Cambridge, Faculty of Economics. Cambridge Working Papers in Economics, n. 0435. doi: https://doi.org/10.17863/CAM.5113.

Pesaran M.H., (2007). A simple panel unit root test in the presence of cross-section dependence. Journal of Applied Econometrics, 22(2): 256-312. doi: 10.1002/jae.951. 
Pope C.A., Coleman N., Pond Z.A., Burnett R.T., (2019). Fine particulate air pollution and human mortality: 25+ $\begin{array}{lllll}\text { years of cohort } & \text { Environmental Research, }\end{array}$ https://doi.org/https://doi.org/10.1016/j.envres.2019.108924.

Pope C.A., Dockery D.W., (2006). Health Effects of Fine Particulate Air Pollution: Lines that Connect. Journal of the Air \& Waste Management Association, 56:6:709-742. https://doi.org/10.1080/10473289.2006.10464485.

Pope C.A., Dockery D.W., (2013). Air pollution and life expectancy in China and beyond. PNAS, 110(32):1286112862. https://doi.org/10.1073/pnas.1310925110.

Powell, D., (2016). Quantile Regression with Nonadditive Fixed Effects. RAND Labor and Population Working Paper, April, 1-22.

Rasli A.M., Qureshi M.I., Isah-Chikaji A., Zaman K., Ahmad M., (2018). New toxics, race to the bottom and revised environmental Kuznets curve: The case of local and global pollutants. Renewable and Sustainable Energy Reviews, 81:3120-3130. https://doi.org/10.1016/j.rser.2017.08.092.

Respiratory Health Association (RHA), (2017). The Electricity You Generate and the Air You Breathe: The Lung Health Benefits of Investing in Clean, Renewable Electricity.

Riojas-Rodríguez H., Silva A.S., Texcalac-Sangrador J.S., Moreno-Banda G.T., (2016). Air pollution management and control in Latin America and the Caribbean: implications for climate change. Revista Panam Salud Publica, 40(3):150-59. URL: https://www.scielosp.org/pdf/rpsp/v40n3/1020-4989-RPSP-40-03-150.pdf.

Ritchie H., Roser M., (2020). Air Pollution. Published online at OurWorldInData.org. URL: https://ourworldindata.org/air-pollution.

Robalino-López A., Mena-Nieto Á., García-Ramos J.E., Golpe A.A., (2015). Studying the relationship between economic growth, CO2 emissions, and the environmental Kuznets curve in Venezuela (1980-2025). Renewable and Sustainable Energy Reviews, 41:602-614. https://doi.org/10.1016/j.rser.2014.08.081.

Romieu I., Gouveia N., Cifuentes L.A., (2012). Multicity Study of Air Pollution and Mortality in Latin America (The ESCALA Health Study). Effects Institute. URL: https://www.healtheffects.org/publication/multicity-study-air-pollution-and-mortality-latin-americaescala-study.

Romieu I., Weitzenfeld H., Finkelman J., (1990). Urban Air Pollution in Latin America and the Caribbean. Journal of the Air, Waste Management Association, 41:9:1166-1171. doi: https://doi.org/10.1080/10473289.1991.10466910.

Royston P., (1983). A simple method for evaluating the Shapiro-Francia W' test for non-normality. Statistician, 32:297-300. doi: 10.2307/2987935.

Santiago R., Koengkan M., Fuinhas J.A., Marques A.C., (2019). The relationship between public capital stock, private capital stock and economic growth in the Latin American and Caribbean countries. International Review of Economics, p. 1-25. doi: 10.1007/s12232-019-00340-x.

Sapkota P., Bastola U., (2017). Foreign direct investment, income, and environmental pollution in developing countries: Panel data analysis of Latin America. Energy Economics, 64:206-212. https://doi.org/10.1016/j.eneco.2017.04.001.

Shafiei S., Salim R.A., (2014). Non-renewable and renewable energy consumption and CO2 emissions in OECD countries: A comparative analysis. Energy Policy, 66:547-556. https://doi.org/10.1016/j.enpol.2013.10.064.

Shahsavari A., Akbari M., (2018). Potential of solar energy in developing countries for reducing energy-related emissions. Renewable and Sustainable Energy Reviews, 90:275-291. https://doi.org/10.1016/j.rser.2018.03.065.

U.S. Environmental Protection Agency (EPA), (2018). Quantifying the Multiple Benefits of Energy Efficiency and Renewable Energy: A Guide for State and Local Governments. PART ONE The Multiple Benefits of Energy Efficiency and Renewable Energy, p. 4-17.

Van-Ruijven B.J., Daenzer K., Fisher-Vanden K., Kober T., Paltsev S., Beach R.H., Calderon S.L., Calvin K., Labriet M., Kitous A., Lucena A.F.P., Van Vuuren D.P., (2016). Baseline projections for Latin America: base-year assumptions, key drivers and greenhouse emissions. Energy Economics, 56:499-512. https://doi.org/10.1016/j.eneco.2015.02.003.

Vásquez I., (1996). The Brady plan and market-based solutions to debt crises. Cato Journal, 16(2):1-11. URL: https:/www.cato.org/sites/cato.org/files/serials/files/cato-journal/1996/11/cj16n2-4.pdf. 
Vodonos A., Awad Y. A., Schwartz J., (2018). The concentration-response between long-term PM 2.5 exposure and mortality; A meta-regression approach. Environmental Research, 166:677-689. https://doi.org/10.1016/j.envres.2018.06.021.

Washburn C., Pablo-Romero M., (2019). Measures to promote renewable energies for electricity generation in Latin American countries. Energy Policy, 128:212-222. https://doi.org/10.1016/j.enpol.2018.12.059.

World Bank Open Data, (2020). URL: http://www.worldbank.org/.

World Health Organization (WHO)., (2020). Air pollution. URL: https://www.who.int/health-topics/air-pollution.

Yang J., Li X., Peng W., Wagner F., Mauzerall D.L., (2018). Climate, air quality and human health benefits of various solar photovoltaic deployment scenarios in China in 2030, Environmental Research Letters 13(6): 064002. doi: 10.1088/1748-9326/aabe99.

Yao S., Zhang S., Zhang X., (2019). Renewable energy, carbon emission and economic growth: A revised environmental Kuznets Curve perspective. Journal of Cleaner Production, 235:1338-1352. https://doi.org/10.1016/j.jclepro.2019.07.069.

Zaman K., Abd-el Moemen M., (2017). The influence of electricity production, permanent cropland, high technology exports, and health expenditures on air pollution in Latin America and the Caribbean Countries. Renewable and Sustainable Energy Reviews, 76:1004-1010. https://doi.org/10.1016/j.rser.2017.03.103. 